\title{
Comprehensive analysis of chemical and biological problems associated with browning agents used in aquatic studies
}

\author{
Kristin Scharnweber $\left(\mathbb{D},{ }^{1,2} *\right.$ Sari Peura $\left(\mathbb{C}^{1,1,3}\right.$ Katrin Attermeyer ${ }^{(0,},{ }^{1,4}$ Stefan Bertilsson, ${ }^{1,5}$ Lucas Bolender, \\ Moritz Buck, ${ }^{1,3}$ Karólína Einarsdóttir, ${ }^{1}$ Sarahi L. Garcia $\mathbb{D}^{1},{ }^{1,6}$ Raphael Gollnisch ${ }^{\left(\mathbb{0},{ }^{7}\right.}$ Charlotte Grasset $\mathbb{D}^{1}, 1$ \\ Marloes Groeneveld, ${ }^{1}$ Jeffrey A. Hawkes ${ }^{(1)}{ }^{8}$ Eva S. Lindström, ${ }^{1}$ Christin Manthey, ${ }^{1,9}$ Robyn Övergaard, ${ }^{1}$ \\ Karin Rengefors, ${ }^{7}$ Vicente T. Sedano-Núñez, ${ }^{1,10}$ Lars J. Tranvik ${ }^{\circledR},{ }^{1}$ Anna J. Székely ${ }^{10}{ }^{1,5}$ \\ ${ }^{1}$ Department of Ecology and Genetics, Limnology, Uppsala University, Uppsala \\ ${ }^{2}$ University of Potsdam, Plant Ecology and Nature Conservation, Potsdam, Germany \\ ${ }^{3}$ Department of Forest Mycology and Plant Pathology, Science for Life Laboratory, Swedish University of Agricultural Sciences, \\ Uppsala, Sweden \\ ${ }^{4}$ WasserCluster Lunz, Lunz am See, Austria \\ ${ }^{5}$ Department of Aquatic Sciences and Assessment, Swedish University of Agricultural Sciences, Uppsala, Sweden \\ ${ }^{6}$ Department of Ecology, Environment, and Plant Sciences, Science for Life Laboratory, Stockholm University, Stockholm, \\ Sweden \\ ${ }^{7}$ Department of Biology, Lund University, Lund, Sweden \\ ${ }^{8}$ Analytical Chemistry, Department of Chemistry BMC, Uppsala University, Uppsala, Sweden \\ ${ }^{9}$ Evolutionary Biology, Freie Universität Berlin, Institute of Biology, Berlin-Dahlem, Germany \\ ${ }^{10}$ Molecular Evolution, Department of Cell and Molecular Biology BMC, Uppsala University, Uppsala, Sweden
}

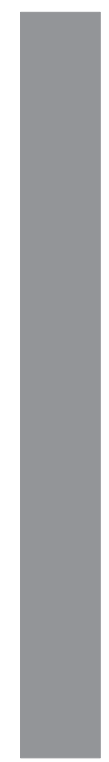

\begin{abstract}
Inland waters receive and process large amounts of colored organic matter from the terrestrial surroundings. These inputs dramatically affect the chemical, physical, and biological properties of water bodies, as well as their roles as global carbon sinks and sources. However, manipulative studies, especially at ecosystem scale, require large amounts of dissolved organic matter with optical and chemical properties resembling indigenous organic matter. Here, we compared the impacts of two leonardite products (HuminFeed and SuperHume) and a freshly derived reverse osmosis concentrate of organic matter in a set of comprehensive mesocosm- and laboratory-scale experiments and analyses. The chemical properties of the reverse osmosis concentrate and the leonardite products were very different, with leonardite products being low and the reverse osmosis concentrate being high in carboxylic functional groups. Light had a strong impact on the properties of leonardite products, including loss of color and increased particle formation. HuminFeed presented a substantial impact on microbial communities under light conditions, where bacterial production was stimulated and community composition modified, while in dark potential inhibition of bacterial processes was detected. While none of the browning agents inhibited the growth of the tested phytoplankton Gonyostomum semen, HuminFeed had detrimental effects on zooplankton abundance and Daphnia reproduction. We conclude that the effects of browning agents extracted from leonardite, particularly HuminFeed, are in sharp contrast to those originating from terrestrially derived dissolved organic matter. Hence, they should be used with great caution in experimental studies on the consequences of terrestrial carbon for aquatic systems.
\end{abstract}

*Correspondence: scharnweber@uni-potsdam.de

Additional Supporting Information may be found in the online version of this article.

This is an open access article under the terms of the Creative Commons Attribution-NonCommercial License, which permits use, distribution and reproduction in any medium, provided the original work is properly cited and is not used for commercial purposes.
Inland waters process large amounts of terrestrial organic carbon (Cole et al. 2007; Drake et al. 2018; Tranvik et al. 2018). In the last decades, increasing concentrations of terrestrially derived dissolved organic matter (DOM) in aquatic systems of the Northern hemisphere, known as "browning," has been described (Monteith et al. 2007; Solomon et al. 2015). Browning has diverse consequences for aquatic ecosystems, largely due to the strong absorption of solar radiation by DOM that alters the vertical distribution of heat and light (Fee et al. 1996; Kirk 2011). 
This leads to cooler deep waters while the shading also hampers photosynthesis. Reductions in photosynthesis are directly connected to algal food supply for higher trophic levels such as zooplankton or fish (Kelly et al. 2014). Thus, the change in the light climate has a direct effect on the food web, causing changes in vertical habitat gradients, food web structure, and resource subsidies (Williamson et al. 2015). Furthermore, the increased carbon inputs provide substrates for the microbial loop, causing increased production of greenhouse gases, such as methane and $\mathrm{CO}_{2}$ (Peura et al. 2014). Thus, browning has a high potential to affect ecosystem functioning and water quality, as well as to further aggravate greenhouse gas emissions. In fact, it has become a primary subject of experimental studies targeting climate change impacts on freshwaters (Weyhenmeyer et al. 2016; Bergström and Karlsson 2019; Vasconcelos et al. 2019).

One challenge of experimental studies of browning is to find a browning agent that can be applied at different experimental scales and ideally enables disentangling the impact of increasing organic carbon substrates from the impact of physical darkening of the water column. Browning agents previously applied include extracts of humic substances from soils (Lennon and Cottingham 2008), leachates from organic material (Geddes 2009), or the use of DOC-rich waters (Kritzberg et al. 2014). However, obtaining sufficient quantities of such materials to enable experimental manipulation at mesocosm or ecosystem scale is challenging and time consuming. A further challenge is that organic matter concentrates derived from humic ecosystems may consist of a diverse and temporally variable mix of carbon compounds leading to unreproducible results. Therefore, large-scale browning experiments (mesocosm or whole-ecosystem experiments) tend to rely on commercially available products as experimental browning agents. Most commonly, leonardite (i.e., oxidized lignite) products are used, which were originally manufactured for agricultural applications such as soil management or feed amendment (Quilty and Cattle 2011). In experiments, these products have been assumed to mimic the natural browning phenomenon, by being fairly recalcitrant and of poor nutritional quality while having similar physical and chemical properties as those of indigenous terrestrial DOM (Lennon et al. 2013), or by being considered inert browning agents with no significant impact on the total bioreactive carbon (Lebret et al. 2018). However, there are indications that the use of these leonardite products may present problems in browning studies. For example, UrrutiaCordero et al. (2017) reported the need to frequently resupply the leonardite product HuminFeed during the course of an experiment in order to maintain the desired increase in water color. Lennon et al. (2013) also described high flocculation rates of the leonardite product SuperHume when used in alkaline ponds as sinking of particles to the sediment exported 5-12\% of the total dissolved organic carbon (DOC) pool daily.

Indeed, environmental conditions affect the behavior of browning agents in both natural and experimental settings. In lakes, formation of particles can be promoted by, for example, sunlight (von Wachenfeldt et al. 2008; Porcal et al. 2013), pH, microbial activity (von Wachenfeldt et al. 2009), and high concentrations of multivalent ions, in particular $\mathrm{Ca}^{2+}$ and $\mathrm{Mg}^{2+}$, which are typical for high alkalinity (i.e., hard water) lakes (Abate and Masini 2003). In addition, the fate of DOM compounds in freshwater ecosystems depends on their chemical composition, affecting their susceptibility to both photochemical and biological degradation (Kellerman et al. 2014; Mostovaya et al. 2017). Sunlight mediated photoreactions can both completely mineralize DOC molecules or modify their bioavailability through the alteration of the molecular structure (Wetzel et al. 1995; Moran and Zepp 1997). As the nature of the leonardite products used in browning experiments is largely unknown, the consequences of their exposure to sunlight and other environmental conditions are unpredictable and uncertain.

The bioavailability of the browning agents used in manipulation studies and their effects on the microbial loop are crucial aspects that must be considered when evaluating their suitability in browning experiments. While the terrestrial DOM responsible for natural browning of freshwaters contains a labile fraction that serves as a carbon source for heterotrophic bacteria (Guillemette et al. 2016), the leonardite browning agents used in experiments are believed to rather exclusively mimic the water color changes of the browning process (Lebret et al. 2018). However, while the effects of browning agents on bacterial communities and their functions remain unknown, Lennon et al. (2013) showed that certain bacterial strains can use leonardite browning agents as a sole carbon source.

Additionally, leonardite products, such as HuminFeed and SuperHume, may contain compounds that are harmful or even toxic to organisms at higher trophic levels. Saebelfeld et al. (2017) reported that HuminFeed negatively impacts reproduction and causes stress response in cultures of the cladocerans Daphnia magna and Daphnia longispina. In contrast, Lennon et al. (2013) did not observe any negative effects of SuperHume on cultures of Daphnia pulex $\times$ pulicaria. Instead, they found a slight increase in fitness due to an earlier age at first reproduction.

While there are indications that leonardite browning agents interfere with bacteria and zooplankton, their impacts on phytoplankton have not been adequately studied. In the browning context, the invasive microalgae Gonyostomum semen (Raphidophyceae) is of particular interest as it causes extensive blooms in brown-water lakes (Rengefors et al. 2012). Thus, there is a strong ecological and societal interest in understanding the factors influencing the mass development of this algae by conducting experimental studies under browning conditions, potentially using leonardite products.

This study aims to assess the feasibility of using different browning agents commonly applied in aquatic browning manipulations, by comparing their effects under different environmental conditions. The experiments were done independently of each other during different projects leading to 
differences in the usage of browning agents and included treatments (see Table 1 for a summary of experiments conducted).

However, combined they represent a valuable set of experiments addressing the suitability of browning agents in aquatic studies from multiple perspectives. This gave us the opportunity to study the effects of two commercially available leonardite products that are widely used in aquatic manipulation studies (i.e., "HuminFeed," hereafter called HF, and "SuperHume," hereafter called SH), a reverse osmosis concentrate extracted from a humic aquatic ecosystem ("reverse osmosis," hereafter called RO) as well as the mix of the two $(\mathrm{HF}+\mathrm{RO})$ to assess their combined effects. We characterized the browning agents chemically and tested whether they would act as an inert carbon source or if they would be bioavailable and, thus, subsidize the food web. We hypothesized that leonardite products are more potent light climate modifiers than an ecosystem derived RO concentrate, whereas the later reflect better the subsidy effect of allochthonous carbon. Meanwhile a mixed treatment containing both kinds of browning agent has simultaneously both effects. A mesocosm study was conducted to test responses at seminatural scale, and several complementary laboratory experiments addressed specific processes. We assessed effects of the browning agents on both abiotic (chemical diversity and particle formation of organic matter), and biotic parameters (including bacterial production [BP], bacterial community composition [BCC], phytoplankton growth, as well as zooplankton abundance and life history).

\section{Use materials and procedures}

\section{Description of browning agents}

HuminFeed (HuminTech $\mathrm{GmbH}$ ) is a commercially available food supplement for animal livestock. It is a water-soluble dry powder produced from alkaline extraction of oxidized lignite (leonardite). According to the manufacturer, it consists of $82 \%$ humic substances, $18 \%$ compounds of lower molecular weights, and no polysaccharides. To our knowledge, this agent has only been used in browning studies across Europe (Meinelt et al. 2007; Saebelfeld et al. 2017; Urrutia-Cordero et al. 2017; Lebret et al. 2018).

SuperHume (CropMaster, United Agricultural Services of America), another commercially available leonardite product, is a liquid containing $4 \%$ fulvic and $8 \%$ humic acids according to the manufacturer's specification. This browning agent has been used in several studies of the browning phenomenon in Northern America (Lennon et al. 2013; Muscarella et al. 2016; Weidel et al. 2017).

For comparison, we also used a reverse osmosis apparatus to produce a humic DOM concentrate from water collected from a local humic stream draining a forested wetland in Central Sweden $\left(59^{\circ} 55^{\prime} 05.0^{\prime \prime} \mathrm{N}, 17^{\circ} 20^{\prime} 49.3^{\prime \prime} \mathrm{E}\right)$. After an initial filtration through $0.2 \mu \mathrm{m}$ pore size membrane filters and subsequent passage through a cation exchange resin (Dowex $^{\circledR}$ 50W X8, Dow Chemical Company), the eluate was concentrated by reverse osmosis using a Real Soft PROS/2S unit (RealSoft) as described by Serkiz and Perdue (1990), to a final concentration of approximately $800 \mathrm{mg} \mathrm{C} \mathrm{L}^{-1}$. To obtain sufficient concentrate for our mesocosm experiment, we processed 3900 liters of stream water that had a concentration of $38 \mathrm{mg} \mathrm{C} \mathrm{L}^{-1}$, which required approximately $90 \mathrm{~h}$ of on-site filtration. We further used a commercially available RO concentrate: Suwannee River Fulvic Acid (SRFA; International Humic Substances Society, Batch 2S101F).

\section{Chemical characterization of browning agents}

We analyzed metals in digested samples of $\mathrm{HF}, \mathrm{SH}$, and $\mathrm{RO}$ by inductively coupled plasma adsorption emission spectroscopy (ICP AES) using a Spectro Ciros CCD ICP-AES (Spectro) as described in Appendix 1a. To identify the chemical properties of the different browning agents, we used nuclear magnetic resonance (NMR) to determine proton chemical environments using a Bruker advanced Neo $600 \mathrm{MHz}$ spectrometer ( ${ }^{1} \mathrm{H}$ NMR: $600.18 \mathrm{MHz}$ ), equipped with a cryogenic tippled resonance probe TCI (CRPHe TR-1H \&19F/13C/15N $5 \mathrm{~mm}-\mathrm{EZ}$ ) as described in Appendix 1b. To measure the size, charge and mass distribution of the material High Pressure Size Exclusion Chromatography - High Resolution Mass Spectrometry (HPSEC-HRMS) was conducted with an Agilent 1100 HPLC (Agilent) equipped with a UV-Vis Diode Array Detector for sample light attenuation (Agilent 1100) and an Orbitrap mass spectrometer (LTQ-Velos Pro, Thermo Fisher Scientific) in series that detected negatively ionizable molecules by electrospray ionization mass spectrometry, as described in Hawkes et al. (2019) and Appendix 1c. Solutions of HF, SH, and SRFA in deuterated water (99.96\%, Eurisotop) were prepared to $4.3,5.6$, and $1.25 \mathrm{mg} \mathrm{mL}^{-1}$, respectively. More details of the chemical characterization methods can be found in the Supplementary Material Appendix 1.

\section{Mesocosm study: In situ responses to browning agents}

The effect of two different browning agents (HF and RO) and their combination (i.e., HF + RO) was assessed by a mesocosm experiment implemented for 4 weeks between 15 June and 13 July in 2016. The mesocosm facility consisted of 20 high-density polyethylene, white opaque, open top cylinders of $2 \mathrm{~m}$ depth and a diameter varying between 92 and $101 \mathrm{~cm}$. It was located in Lake Erken $\left(59^{\circ} 50^{\prime} 09.6^{\prime \prime} \mathrm{N}\right.$, $18^{\circ} 37^{\prime} 52.3^{\prime \prime} \mathrm{E}$ ), held and fixed to a floating wooden jetty close to the lake shore. Details of the experimental setup can be found in Nydahl et al. (2019). In short, after filling the mesocosms with lake water, four treatments with five replicates of the following DOC concentrations (mean \pm standard error) were established: Control $\left(13.0 \pm 0.05 \mathrm{mg} \mathrm{C}^{-1}\right)$, HF $\left(18.4 \pm 0.06 \mathrm{mg} \mathrm{C} \mathrm{L}^{-1}\right)$, RO $\left(18.1 \pm 0.10 \mathrm{mg} \mathrm{C} \mathrm{L}^{-1}\right)$, and HF $+\mathrm{RO}\left(23.5 \pm 0.05 \mathrm{mg} \mathrm{C} \mathrm{L}^{-1}\right)$. Every week an integrated water sample of 15-18 liters was collected from each mesocosm using a $1.5 \mathrm{~m}$ long tube sampler, to analyze water color, 
Table 1. Overview of experiments and most important outcome for evaluating the effects of browning agents.

\begin{tabular}{|c|c|c|c|c|}
\hline Experiment & $\begin{array}{l}\text { Browning } \\
\text { agent }\end{array}$ & $\begin{array}{l}\text { Manipulated } \\
\text { parameter(s) }\end{array}$ & Response variable & Most important measured effect \\
\hline \multirow[t]{3}{*}{$\begin{array}{l}\text { Chemical } \\
\text { characterization }\end{array}$} & $\mathrm{HF}, \mathrm{SH}, \mathrm{RO}$ & & Metal content & $\begin{array}{l}\text { Elevated } \mathrm{Al}, \mathrm{Fe}, \mathrm{Na} \text { in } \mathrm{HF} \\
\text { Elevated } \mathrm{Ca} \text { in } \mathrm{SH}\end{array}$ \\
\hline & $\mathrm{HF}, \mathrm{SH}, \mathrm{SRFA}$ & & $\begin{array}{l}\text { Chemical properties by } \\
\text { NMR }\end{array}$ & $\begin{array}{l}\text { More aromatic compounds in } \mathrm{HF} \text { and } \mathrm{SH} \\
\text { More carboxylic rich alicyclic material and } \\
\text { carbohydrates in SRFA }\end{array}$ \\
\hline & $\mathrm{HF}, \mathrm{SH}, \mathrm{SRFA}$ & & $\begin{array}{l}\text { Size, charge and mass } \\
\text { distribution by } \\
\text { HPSEC-HRMS }\end{array}$ & $\begin{array}{l}\text { No carboxylic acids in } \mathrm{HF} \text { and } \mathrm{SH} \\
\text { High molecular weight aromatics in } \mathrm{HF} \text { and } \mathrm{SH}\end{array}$ \\
\hline \multirow[t]{3}{*}{ Mesocosm study } & $\mathrm{HF}, \mathrm{RO}, \mathrm{HF}+\mathrm{RO}$ & & $\begin{array}{l}\text { Water color } \\
\text { Particulate matter }\end{array}$ & $\begin{array}{l}\text { Decrease in the first week for } \mathrm{HF} \text { and } \mathrm{HF}+\mathrm{RO} \\
\text { Increase during experiment for } \mathrm{HF} \text { and } \mathrm{HF} \\
\quad+\mathrm{RO}\end{array}$ \\
\hline & & & $\mathrm{BCC}$ & Different for HF and HF + RO \\
\hline & & & $\begin{array}{l}\text { Zooplankton } \\
\text { abundance }\end{array}$ & Lower abundance for $\mathrm{HF}$ and $\mathrm{HF}+\mathrm{RO}$ \\
\hline \multirow[t]{6}{*}{ Microbial test } & $\mathrm{HF}, \mathrm{RO}, \mathrm{HF}+\mathrm{RO}$ & Light & Water color & $\begin{array}{l}\text { Decrease in light treatment for } \mathrm{HF}, \mathrm{RO}, \mathrm{HF} \\
\quad+\mathrm{RO} \\
\text { Highest decrease for } \mathrm{HF} \text { and } \mathrm{HF}+\mathrm{RO}\end{array}$ \\
\hline & & & POC & $\begin{array}{l}\text { Increase with } \mathrm{HF}, \mathrm{RO}, \mathrm{HF}+\mathrm{RO} \\
\text { Highest increase for } \mathrm{RO} \text { in light }\end{array}$ \\
\hline & & & DOC, TOC & $\begin{array}{l}\text { In light: decrease of TOC in all treatments but } \\
\text { control } \\
\text { Highest decrease for HF, HF + RO in light } \\
\text { Higher decrease for HF and HF + RO in light } \\
\text { than in dark }\end{array}$ \\
\hline & & & DOM quality (EEMs) & $\begin{array}{l}\text { Effect of light for all treatments but control } \\
\text { Notable differences in light between HF } \\
\text { samples (HF and HF + RO) and RO only }\end{array}$ \\
\hline & & & BP & $\begin{array}{l}\text { Different effect of browning agents under dark } \\
\text { and light conditions } \\
\text { Changing effect over time for HF in light }\end{array}$ \\
\hline & & & $\mathrm{BCC}$ & $\begin{array}{l}\text { Effect of browning agents and light conditions } \\
\text { More substantial effect of browning agents, } \\
\text { especially HF and HF + RO in light }\end{array}$ \\
\hline Alkalinity test & $\mathrm{HF}, \mathrm{SH}, \mathrm{RO}$ & $\begin{array}{l}\text { Light and } \\
\text { alkalinity }\end{array}$ & DOM quality (EEMs) & $\begin{array}{l}\text { Increased formation for HF and SH only in hard } \\
\text { water } \\
\text { Effect of light only in hard water } \\
\text { Effect of light for RO } \\
\text { Effect of light for HF and SH but only in hard } \\
\text { water }\end{array}$ \\
\hline $\begin{array}{l}\text { Ecotoxicological } \\
\text { assay D. magna }\end{array}$ & $\mathrm{HF}, \mathrm{SH}, \mathrm{RO}$ & - & $\begin{array}{l}\text { Mobilization, } \\
\text { reproduction }\end{array}$ & $\begin{array}{l}\text { Net reproductive rate lowest in } \mathrm{HF} \\
\text { Average number of offspring per clutch lower } \\
\text { with } \mathrm{RO}, \mathrm{HF} \text {, and } \mathrm{SH} \\
\text { Lower number of offspring in the HF treatment }\end{array}$ \\
\hline G. semen growth & $\begin{array}{l}\mathrm{HF}, \mathrm{SH}, \mathrm{RO} \\
\text { (three concentrations } \\
\text { each) }\end{array}$ & - & Cell density & $\begin{array}{l}\text { In RO treatments: Contamination of cultures } \\
\text { In high concentrations of HF lower growth rate } \\
\text { compared to lower concentration }\end{array}$ \\
\hline
\end{tabular}


particle formation (i.e., particulate matter formation), BCC, and zooplankton abundance.

Zooplankton samples were collected by filtering 5 liters of water through $55 \mu \mathrm{m}$ plankton net, and preserving the zooplankton in Lugol's solution. Zooplankton was counted and species abundances were determined using an inverted microscope (Leica, DM, IL LED Fluo, Leica Microsystems GmbH). The immediate impact of the two browning agents on the abundance of Copepoda and Cladocera was evaluated at the first sampling campaign, that is, approximately $16 \mathrm{~h}$ after the addition of the browning agents.

\section{Microbial test: Effects on bacteria and interaction of light and browning agents}

In order to assess the effect of light exposure on the browning agents, a laboratory scale experiment was performed with similar treatments as in the mesocosms but with different light conditions (hereafter called the microbial test). Four 1-liter replicates of the $\mathrm{HF}, \mathrm{RO}, \mathrm{HF}+\mathrm{RO}$, and control treatments (initial DOC concentration: $18.0,22.2,27.1$, and $12.9 \mathrm{mg} \mathrm{C} \mathrm{L}^{-1}$, respectively) were placed either in ambient daylight at a window facing west or in the dark for $22 \mathrm{~d}$. These incubations were both performed at room temperature in an air-conditioned location. Prior to the addition of the browning agents (HF and RO), the water was filtered through Whatman GF/F filters to remove larger particles, microeukaryotes, zooplankton, and phytoplankton. All treatments were sampled for BP and water color at six time points (start, 6, 24, 120, 336, and $528 \mathrm{~h}$ ), and for particulate organic carbon (POC), DOC, and DOM quality measurements by fluorescence excitation emission matrix (EEM) spectroscopy at the beginning and end (0 and $528 \mathrm{~h})$. BCC was assessed only at the end of the experiment (528 h).

\section{Alkalinity test: Interaction of water hardness and browning agents}

To assess whether the interaction of light and browning agents depends on water hardness (measured as alkalinity and conductivity), and to compare this for the two most commonly used leonardite browning agents (i.e., $\mathrm{HF}$ and $\mathrm{SH}$ ), a second laboratory experiment was performed (hereafter called the alkalinity test). The experiment was conducted using the three different browning agents ( $\mathrm{HF}, \mathrm{SH}$, and $\mathrm{RO}$ ) added to water from Lake Erken, which is characterized by hard water (alkalinity: $1.81 \mathrm{meq} \mathrm{L}^{-1}$; conductivity: $27.4 \mathrm{mS} \mathrm{m}^{-1}$; Swedish National Data Service 2020), or to water from Lake Ljustjärn $\left(59^{\circ} 55^{\prime} 23.1^{\prime \prime} \mathrm{N}, 1^{\circ} 27^{\prime} 18.5^{\prime \prime} \mathrm{E}\right)$, characterized by soft water (alkalinity: $0.08 \mathrm{meq} \mathrm{L}^{-1}$; conductivity: $4.45 \mathrm{mS} \mathrm{m}^{-1}$; Sobek et al. 2003). Prior to the experiment, the waters of both lakes were prefiltered through a $50 \mu \mathrm{m}$ mesh-size plankton net to remove zooplankton and larger particles. For the browning agent treatments (HF, SH, and $\mathrm{RO}$ ), $10 \mathrm{mg} \mathrm{TOC} \mathrm{L}^{-1}$ of each of the agents were added to water from both lakes, respectively, and then incubated in light or dark. The light treatment was performed by incubating the bottles first outside in natural sunlight for $7 \mathrm{~d}$ (temperature between $8^{\circ} \mathrm{C}$ and $22^{\circ} \mathrm{C}$ ), and subsequently in a dark constant temperature room $\left(20^{\circ} \mathrm{C}\right)$ for another 7-8 d. The dark incubations were kept for the entire experiment $(14 \mathrm{~d})$ in the dark constant temperature room. All treatments were performed in $500 \mathrm{~mL}$ glass bottles in triplicates. All bottles were sampled for particulate matter concentration and DOM quality assessment by fluorescence EEM spectroscopy measurements on the first and last day of the incubations.

Ecotoxicological assay: Zooplankton life history responses

To assess the effect of the browning agents RO, HF, and $\mathrm{SH}$ on the life history of zooplankton, we used an acute immobilization test (OECD standard 202) and a reproduction test (OECD standard 211) with lab cultures of D. magna. The daphnids originated from a single clone (environmental pollution test strain Klon 5 of the State Office for Nature, Environment, and Customer protection North-Rhine Westfalia, Bonn, Germany) and were cultured in glass beakers containing M7 media (OECD standards 202 and 211) under a constant temperature of $20^{\circ} \mathrm{C}$, and a $16: 8 \mathrm{~h}$ light : dark cycle. The animals were fed three times a week with 0.1$0.2 \mathrm{mg}$ C of the green algae Pseudokirchneriella subcapitata per Daphnia and day. These algae were maintained in culture medium (OECD standard 201) with sparged air under constant daylight conditions and $20^{\circ} \mathrm{C}$. Algal concentrations were determined using a flow cytometer (Parctec CyFlow Space).

The immobilization test was carried out for $48 \mathrm{~h}$ under constant temperature and light cycle (as described above). No food was provided during this test. For each browning agent (diluted in M7 medium) and a control (pure M7 medium), four replicate vials were adjusted for browning agent concentrations of $5,10,20$, and $30 \mathrm{mg} \mathrm{C} \mathrm{L}^{-1}$. Five individual neonates born within $24 \mathrm{~h}$ were placed in each vial containing $10 \mathrm{~mL}$ of the respective treatment solution. After 24 and $48 \mathrm{~h}$, the number of immobilized daphnids was recorded.

The reproduction experiment was carried out for $21 \mathrm{~d}$ under constant temperature, light cycle, and food conditions (as described above). The browning agents were amended to M7 medium to a concentration of $10 \mathrm{mg} \mathrm{C} \mathrm{L}^{-1}$ and a control was set up with pure M7 medium. We used 12 replicate vials with one neonate per vial. Each day, the daphnids were removed from the vials, separated from their offspring (if applicable), and offspring were counted before returning the original neonates to their respective vials. Medium was refreshed four times during the period of the experiment.

Net reproduction rate was calculated over the $21 \mathrm{~d}$ of the experiment using the formula:

$$
\text { Net reproductive rate }=\sum_{x=0}^{21} l(x) m(x)
$$


where $l(x)$ is the number of individuals surviving to age $x$ (in days), and $m(x)$ is the number of offspring per surviving individual between age $x$ and $x+1$. Furthermore, number of offspring per clutch, total number of offspring, age at first clutch, number of clutches, and number of offspring at first clutch of D. magna was estimated.

\section{Growth dynamics of $G$. semen}

We tested the response of G. semen, a phytoplankton species known to be associated to high water color (Cronberg et al. 1988; Rengefors et al. 2012), to the different browning agents. The experiment was performed using a monoclonal strain of $G$. semen isolated from the humic lake Pabezninkai in Lithuania (Karosienè et al. 2016). The strain was grown in batch mode with an initial cell density of 250 cells $\mathrm{mL}^{-1}$ and a total volume of $30 \mathrm{~mL}$ per cell culture flask (Thermo Scientific Nunc) under constant light intensity (100 $\mu \mathrm{mol}$ photons $\mathrm{m}^{-2} \mathrm{~s}^{-1}$ in a $14: 10 \mathrm{~h}$ light : dark cycle) and constant temperature of $20^{\circ} \mathrm{C}$. Three different concentrations of the three browning agents (HF, SH, and $\mathrm{RO}$ ) were used to test their effect on G. semen growth rates compared to a control $(\mathrm{MWC}+\mathrm{Se}-$ Wright's cryptophyte medium MWC modified from Guillard and Lorenzen 1972), and with an addition of $4.5 \mathrm{nM} \mathrm{Na}_{2} \mathrm{SeO}_{3}$. Concentrations of the three browning agents, dissolved in $\mathrm{MWC}+$ Se medium, were set to low $\left(2.4 \mathrm{mg} \mathrm{L}^{-1}\right)$, medium (7.2 $\left.\mathrm{mg} \mathrm{L}^{-1}\right)$, and high $\left(21.6 \mathrm{mg} \mathrm{L}^{-1}\right)$ levels of DOC. Each treatment including the control had five replicates. Cell density was determined after $12 \mathrm{~d}$ using a FlowCam Benchtop B3 (Fluid Imaging Technologies) equipped with a $300 \mu \mathrm{m}$ flow cell, and specific growth rates $\mu$ per day during the exponential growth phase were calculated from the obtained cell densities as $\mu=\ln \left(N_{t} / N_{0}\right) / \Delta t$.

\section{Chemical analyses of experiments}

Prior to water color, DOC, and EEMs analyses, the water samples were filtered through pre-combusted GF/F filters (Whatman, GE Healthcare). DOC concentration was measured on a Total Carbon Analyzer (Sievers M9 Laboratory Analyzer, GE Analytical Instruments), while EEM spectroscopy for qualitative assessment of DOM was performed as described before (Kothawala et al. 2014). Briefly, the UV-visible absorbance spectra were determined using a Lambda 40 UV-visible spectrophotometer (Perkin Elmer) which was also used for water color determination at $440 \mathrm{~nm}$ (mesocosm study) and $420 \mathrm{~nm}$ (microbial and alkalinity test), while EEMs were obtained using a fluorescence spectrophotometer (SPEX FluoroMax-4, Horiba Jobin Yvon). Milli-Q water was used as blank and its values were subtracted from the EEM, which were also corrected for instrument biases and inner filter effects.

Samples for particulate matter analyses were collected on pre-combusted glass microfiber filters. For total particulate matter quantification the weight of the clean filters was subtracted from the weight of dried filters. For POC analysis in the light test, the samples were collected on GF/F filters and acidified with $10 \% \mathrm{HCl}$ after filtration to remove inorganic carbon prior drying in an exsiccator. Subsequently, POC was analyzed using an Elemental Combustion System (Costech Instruments, Cernusco s/Nav.). Total organic carbon (TOC) was calculated as the sum of POC and DOC.

\section{Microbial analyses of experiments}

The BCC was assessed by filtering approximately $250 \mathrm{~mL}$ of water onto $47 \mathrm{~mm}$ diameter $0.2 \mu \mathrm{m}$ pore-size polyether sulfone membrane filters (Supor-200, Pall Corporation). DNA was extracted from the filters and amplified, sequenced, and the raw sequences were processed as in Segura et al. (2019). Briefly, the V3-V4 region of the bacterial 16S rRNA gene was amplified and sequenced on an Illumina MiSeq platform at National Genomics Infrastructure (NGI, SciLifeLab). The raw sequences were deposited at the European Nucleotide Archive (ENA) under accession number PRJEB48081 and processed into operational taxonomic units (OTUs) using the UNOISE pipeline (Edgar 2016). Samples with less than 5000 reads were removed, leaving 29 samples for the final data analyses. Prior to these analyses, all remaining samples were rarefied to the sample with lowest read count.

Heterotrophic BP was determined immediately after sampling via the measurement of the incorporation rate of $\mathrm{L}^{3} \mathrm{H}$-leucine (Perkin Elmer, specific activity $161 \mathrm{Ci} \mathrm{mmol}^{-1}$ ) into the protein fraction based on the protocol of Smith and Azam (1992) as in Székely et al. (2013).

\section{Data analyses}

Processing of the EEMs was performed using MatLab (MatLab 7.7.0, The MathWorks) and the FDOMcorr toolbox (Murphy et al. 2010) as described before in Kothawala et al. (2014). Based on Fellman et al. (2010), the specific peaks $\mathrm{C}, \mathrm{A}, \mathrm{T}, \mathrm{B}$, and $\mathrm{M}$ were extracted for further qualitative analyses of DOM. All statistical analyses were performed using the $\mathrm{R}$ (version 3.4.3) environment for statistical computing (R Core Team 2018). The effect of the different treatments was assessed by comparing the parameters measured at the end of the experiments (e.g., particulate matter in the alkalinity test). In the case when the initial values of the assessed parameter differed, the relative changes of the parameters during the experiments were calculated by dividing the difference between the final and initial values with the initial value (e.g., absorbance and OC values in the microbial test). Effect of the different treatments were tested by ANOVA, using the $\mathrm{lm}$ and ANOVA function of R. Alternatively, to test the effect of the treatments over time for particulate matter and for BP in the case of the mesocosms experiment and the microbial test, respectively, a mixed effect model was performed using treatment, time, and their interaction as fixed effects and mesocosm ID as random factor. Significant differences between treatments were determined by coefficients of the model or Tukey's post hoc analyses. To fulfill the assumptions 
of the applied ANOVAs, data were log-transformed when necessary (number of offspring at first clutch of D. magna, $\mathrm{Abs}_{420}$, DOC, POC in the microbial test, particulate matter in soft water of the alkalinity test), or inverse-transformed (age at first clutch of D. magna).

Ordination of multivariate data was implemented by nonmetric multidimensional scaling (NMDS) with Euclidean and Bray-Curtis dissimilarity indexes for the change in the specific peaks of EEMs (i.e., difference between initial and final $\mathrm{A}$, $\mathrm{B}, \mathrm{C}, \mathrm{M}$, and T peaks) and bacterial OTUs at the end of the experiment, respectively. The effect of the different treatments was assessed by permutational analyses of variances (PERMANOVA, 999 permutations) on balanced designs to avoid potential problems from heterogeneous dispersions (Anderson and Walsh 2013). All multivariate analyses were performed using the vegan package of $\mathrm{R}$ version 3.6.1. (Oksanen et al. 2017).

\section{Assessment}

\section{Chemical characterization of browning agents}

Compared to $\mathrm{SH}$ and $\mathrm{RO}$, HF had elevated levels of aluminum, iron and sodium, while $\mathrm{SH}$ had higher concentrations of calcium compared to $\mathrm{HF}$ and $\mathrm{RO}$, and higher aluminum and iron than the RO (Table 2).

NMR showed that HF and $\mathrm{SH}$ are both characterized by high abundance of aromatic protons in comparison to SRFA. The abundance of aliphatic "terpenoid-like" protons (0-1.6 ppm) was similar for all three, and SRFA had the highest abundance of carboxylic rich alicyclic material and carbohydrates (Supplementary figure Appendix 2).

HPSEC-HRMS indicated strong light absorbance properties over the chromatographic separation of all three browning agents (Supplementary figure Appendix 3). Only the SRFA sample contained ionizable material in the range 350-450 Da, where DOC is typically found to be at a maximum in mass spectrometric analyses of organic matter from aquatic environments. The elution time of this agent was typical for DOM using this method (Hawkes et al. 2019), between 9 and 12 min. This result indicates that HF and $\mathrm{SH}$ do not contain carboxylic acids, with mass 200-800 Da, which are typical for DOM from aquatic environments-and this corresponds well to the NMR data, as these mixtures also contained little carboxylic rich alicyclic material (Hertkorn et al. 2006). Instead, they are constituted by higher molecular weight aromatic compounds, which may explain their lower solubility and tendency to coagulate (Patriarca et al. 2020).

\section{Abiotic effects: Water color and particle formation}

In the mesocosm study, as expected, the addition of all browning agents (i.e., HF, RO, and $\mathrm{HF}+\mathrm{RO}$ ) increased water color compared to the control (repeated measures ANOVA $\left.F_{3,75}=1532, p<0.001\right)$ and the increase was the most substantial for the treatments containing $\mathrm{HF}$ (i.e., $\mathrm{HF}$ and $\mathrm{HF}+\mathrm{RO}$; Fig. 1a; Appendix 4). However, the color darkening effect of the browning agents decreased with time (effect of sampling time: $F_{4,75}=4.768, p=0.002$ ) and the most substantial changes were detected at the beginning of the experiment between the first and the second sampling (Fig. 1a). Particulate matter concentrations also varied among treatments (repeated measures ANOVA: $\left.F_{3,16}=73.1, p<0.001\right)$ with the highest concentrations also measured in the HF treatments (Fig. 1b). Furthermore, particulate matter concentrations changed over time (repeated measures ANOVA: $F_{4,64}=5.1, p<0.001$ ) with $\mathrm{HF}$ treatments showing increasing particulate matter concentration until the third sampling.

In the microbial test using water from Lake Erken, the different carbon treatments ( $\mathrm{HF}, \mathrm{RO}, \mathrm{HF}+\mathrm{RO}$, and control), the light treatment, and the interaction of the two all had a significant but variable effect on the change in water color and OC concentrations (Table 3). Although there was an initial DOC gradient among the carbon treatments (control $<\mathrm{HF}<\mathrm{RO}<\mathrm{HF}+\mathrm{RO}$ ), the identified patterns of change for DOC, POC, TOC, and color both in light and dark were inconsistent with this initial concentration gradient with the exception of the change of color in dark (Fig. 2). POC was affected by the light treatment, and the interaction of the light treatment and the carbon treatments (Table 3). In the dark incubations, there was no significant decrease in the water color in any of the treatments (Fig. 2, original absorbance values in Supplementary Figure Appendix 5 and statistical tests in Supplementary Material Appendix 6a/I). In the light treatments, water color decreased in all treatments and the decrease was significantly higher in the HF amended treatments ( $\mathrm{HF}$ and $\mathrm{HF}+\mathrm{RO}$ ), than in the $\mathrm{RO}$ or control treatments (Fig. 2a; Supplementary Material Appendix 6a/I). Regarding POC concentration changes, in the dark, the carbon amended samples showed POC increase but this was not significantly different from the relative changes of the control samples under the same conditions (Fig. 2b; Supplementary Material Appendix

Table 2. Chemical composition of HuminFeed, SuperHume, and reverse osmosis dry extracts in $\mu \mathrm{g}$ (mg C added) ${ }^{-1}$. LOD, limit of detection.

\begin{tabular}{lccccrrrr}
\hline Browning agent & Al & As & Ca & Cu & Fe & Na & Ni & Z \\
\hline Huminfeed & 79.31 & 0.078 & 19.9 & 0.061 & 24.016 & 41.576 & 0.097 & 0.265 \\
SuperHume & 10.81 & LLO & 84.9 & $<$ LOD & 8.504 & 11.389 & 0.045 \\
Reverse osmosis & 0.79 & LLOD & 45.3 & $<$ LOD & 1.896 & 8.689 & $<$ LOD & 0.021 \\
\hline
\end{tabular}




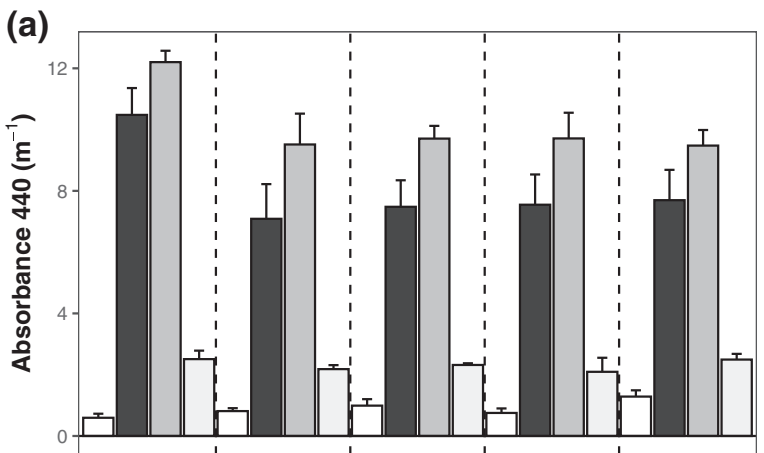

(b)

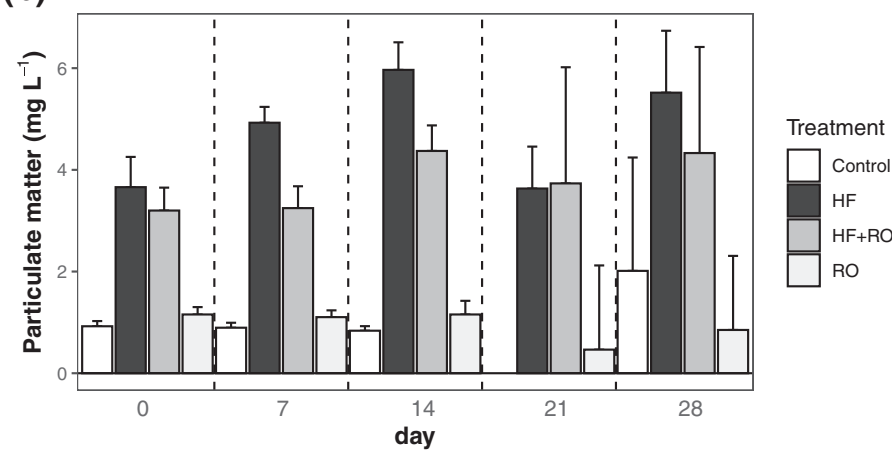

Fig 1. Changes and differences of (a) water color $\left(\mathrm{Abs}_{440}\right)$ and (b) particulate matter concentrations of four different browning agent treatments (control, HF, RO, and the mix of the two [HF + RO]) during the 4 weeks of the mesocosm study.

6a/I). Meanwhile, in the light POC significantly increased in all treatments compared to the dark controls with the highest increases in the samples with added $\mathrm{RO}$ (i.e., $\mathrm{HF}+\mathrm{RO}$ and $\mathrm{RO}$ ) (Fig. 2b; Supplementary Material Appendix 6a/II). However, when DOC was considered or DOC and POC together as TOC, the picture was different. DOC loss was detected in all treatments (Fig. 2c), while TOC loss was detected in all treatments but the control in light (Fig. 2d). In dark, the highest relative loss of both DOC and TOC was measured for the control and RO treatments. However, in the light incubations, the detected DOC and TOC loss showed opposite pattern to the dark treatment with the highest losses seen in the two HF treatments (i.e., $\mathrm{HF}$ and $\mathrm{HF}+\mathrm{RO}$ ) (Fig. 2c,d). Thus, when the results of the different carbon analyses are combined, it is clear that while DOC decreased in all treatments (Supplementary Material Appendix 7), in most cases this could not be explained solely by POC increase as TOC concentration also decreased (Fig. 2b-d). The only exceptions were the HF amended treatments in dark and the control treatment in light where no significant TOC decrease was detected (Supplementary Material Appendix 8).

In the case of the hard water incubations (i.e., water from Lake Erken), particulate matter was significantly affected by both the different added agents (i.e., $\mathrm{HF}, \mathrm{SH}$, and $\mathrm{RO}$ ) and the light conditions but not the interaction of the two types of treatments (Table 3). In both dark and light incubations, the highest increase of particulate matter was measured for treatments with leonardite products (i.e., $\mathrm{HF}$ and $\mathrm{SH}$ ). Although overall, the particulate matter increase was significantly higher in light than in dark, the difference between the dark and light treatment of the corresponding browning agent treatment pairs (e.g., HF in dark compared to HF in light) was not significant (Fig. 2d; Supplementary Material Appendix 6b/I). Unfortunately, the number of replicates decreased from 48 to 41 in the alkalinity test due to bottles breaking during the light incubations. In the case of soft water (i.e., water from Lake Ljustjärn) only the browning agents had a significant effect on the changes of particulate matter, but not the light treatment or the interaction of the two treatments (Table 3). The impact of browning agents was primarily driven by an outlier value in the light HF treatment (Fig. 2e). However, no significant differences between pairwise comparisons could be detected (Supplementary Material Appendix 6b/II).

\section{Abiotic effects: Qualitative DOM changes based on EEMs}

The PERMANOVA of the change of extracted EEM peaks during the microbial and alkalinity tests revealed significant differences between the samples depending on the browning agents (levels: control, $\mathrm{HF}, \mathrm{HF}+\mathrm{RO}, \mathrm{RO}$, and $\mathrm{SH}$ ), water

Table 3. Water color changes (absorbance at $420 \mathrm{~nm}$ ) and flocculation occurring in treatments of the different browning agents (HuminFeed, SuperHume, and reverse osmosis). Results of ANOVAs from the microbial and alkalinity test. Bold font depicts significant effects with $p<0.05$.

Microbial test

\begin{tabular}{|c|c|c|c|c|c|c|c|c|c|c|c|c|}
\hline & \multicolumn{2}{|c|}{$\mathrm{Abs}_{420} *$} & \multicolumn{2}{|c|}{ POC* } & \multicolumn{2}{|c|}{ DOC* } & \multicolumn{2}{|c|}{ TOC } & \multicolumn{2}{|c|}{$\begin{array}{c}\text { Particulate matter } \\
\text { hard water }\end{array}$} & \multicolumn{2}{|c|}{$\begin{array}{c}\text { Particulate matter } \\
\text { soft water* }\end{array}$} \\
\hline & $F$ & $p$ & $F$ & $p$ & $F$ & $p$ & $F$ & $p$ & $F$ & $p$ & $F$ & $p$ \\
\hline Agent & 24.02 & $<0.001$ & 1.829 & 0.188 & 48.54 & $<0.001$ & 21.71 & $<0.001$ & 84.25 & $<0.001$ & 4.261 & 0.027 \\
\hline Light & 352.9 & $<0.001$ & 42.15 & $<0.001$ & 78.75 & $<0.001$ & 46.39 & $<0.001$ & 8.934 & 0.011 & 0.821 & 0.381 \\
\hline Interaction & 19.37 & $<0.001$ & 8.173 & 0.002 & 50.36 & $<0.001$ & 38.06 & $<0.001$ & 2.202 & 0.141 & 1.180 & 0.355 \\
\hline
\end{tabular}

*Log-transformed data. 

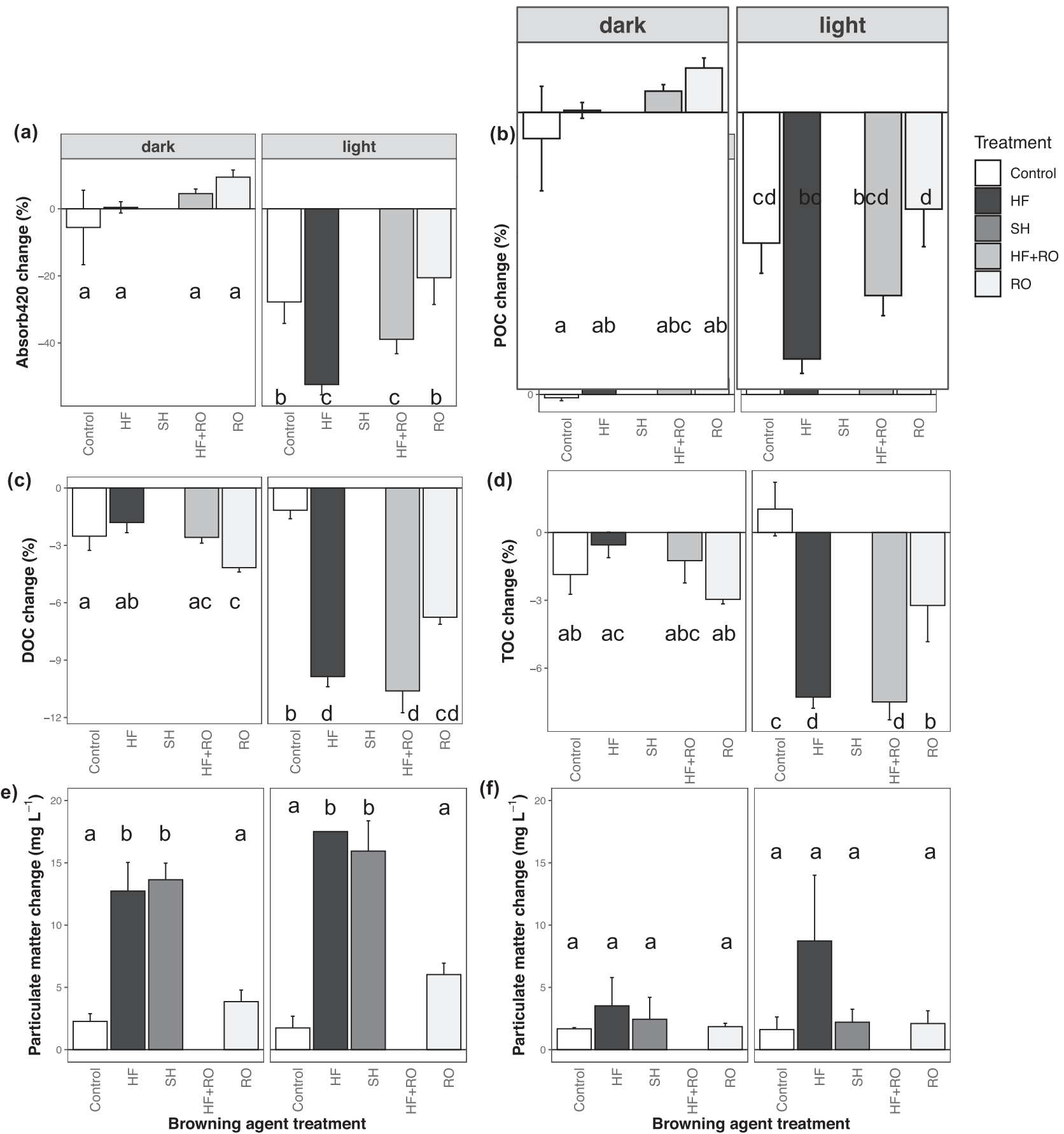

Fig 2. Changes in measured abiotic parameters throughout the microbial ( $22 \mathrm{~d}$ ) and alkalinity test ( $14 \mathrm{~d}$ ) under dark and light treatments using different browning agents (control, RO, HF, SH, the mix of HF and RO [HF + RO]). For the microbial test, (a) changes in water color (Abs 420$)$, (b) POC, (c) DOC, and (d) TOC; and for the alkalinity test, changes in particulate matter in (e) hard water and (f) soft water are shown. Browning agent treatments with the same letter are not significantly different.

hardness and the interaction of these two factors with light (Supplementary Material Appendix 9). The largest difference between treatments was detected for the peak related to substances with high molecular weight and aromatic humic nature (Peak A), in which all the treatments including leonardite
( $\mathrm{HF}+\mathrm{RO}, \mathrm{HF}$, and $\mathrm{SH})$ were distinct from the control in the light treatment in hard water (Supplementary Material Appendix 10a). Also the peak related to biological activity (Peak M) had the same trend with higher values detected for the treatments with leonardite in the light treatment in hard water, although 
(a)

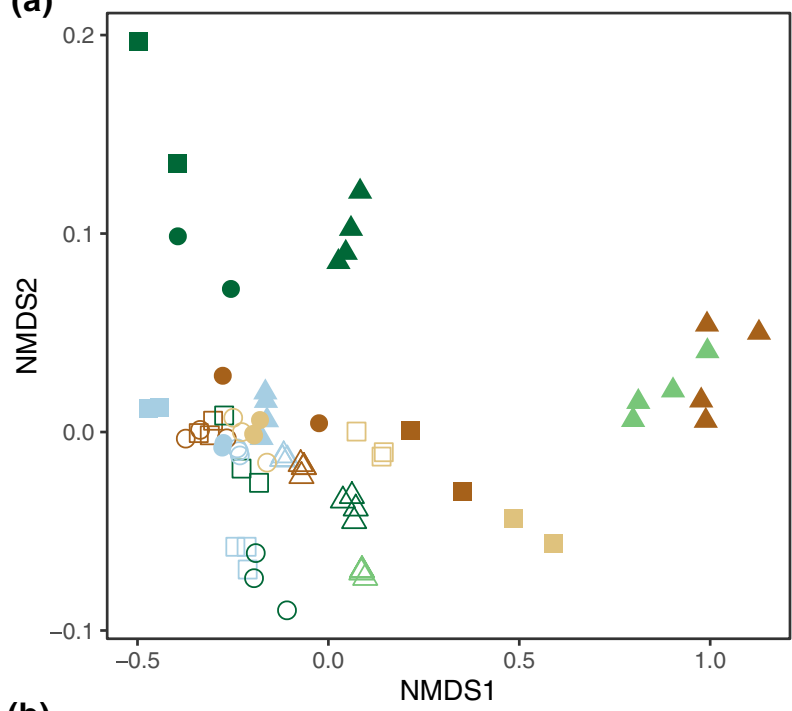

(b)

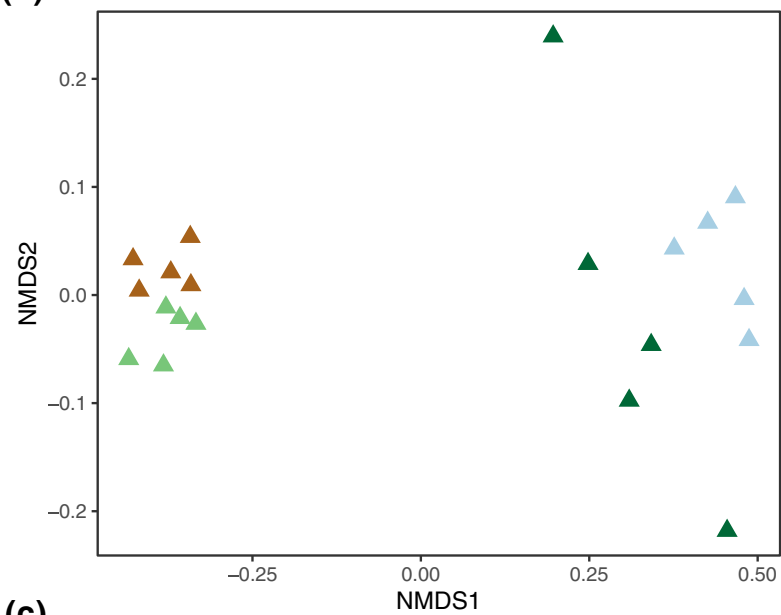

(c)

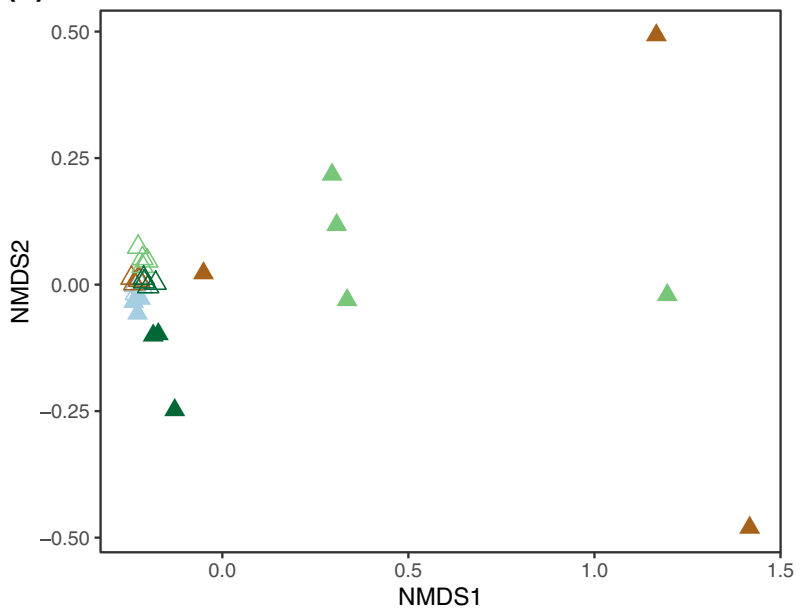

Browning agent

- Control

- $\mathrm{HF}$

- $\mathrm{SH}$

HF+RO

- $R O$

Treatment

$\triangle$ Dark and hard water in microbial test

$\square$ Dark and hard water in alkalinity test

O Dark and soft water in alkalinity test

- Light and hard water in microbial test

- Light and hard water in alkalinity test

- Light and soft water in alkalinity test
Browning agent

$\triangle$ Control

$\triangle \mathrm{HF}$

A $H F+R O$

$\triangle$ RO
Light treatment

$\triangle$ Dark

$\Delta$ Light

Browning agent

- Control

- $\mathrm{HF}$

- $\mathrm{HF}+\mathrm{RO}$

- RO

Fig 3. Ordination by NMDS of multivariate data. (a) Ordination generated using the differences between initial and final values (i.e., changes) of the main peaks of the EEM during the microbial and alkalinity test. (b) Ordination of the BCC at the end of the mesocosm experiment, and (c) at the end of the microbial test. Blue color represents control, brown represents leonardite browning agents (dark brown HF, light brown SH), green represents treatments containing RO (light green $\mathrm{HF}+\mathrm{RO}$, dark green RO). Empty symbols represent continuous dark treatment; filled symbols represent light exposed treatments. Hard water replicates are represented by triangle and square shaped points, while soft water samples are symbolized by round symbols. 


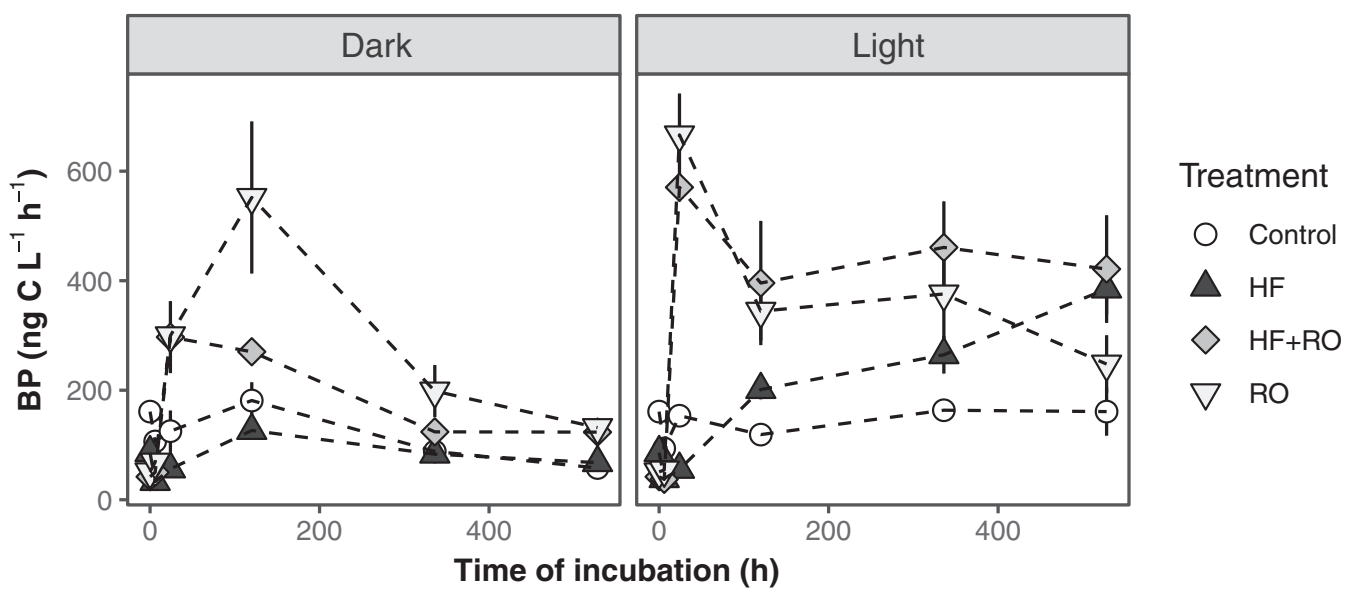

Fig 4. Changes in heterotrophic BP measured by ${ }^{3} \mathrm{H}$-leucine incorporation during the microbial test for samples incubated in dark and light with different browning agents (control, $\mathrm{HF}, \mathrm{RO}$, and the mix of the two [HF + RO]).

the difference was less pronounced than for the peak A (Supplementary Material Appendix 10b). This was supported by the NMDS plot (Fig. 3a), which also showed clear differences among the treatments as the samples in the light treatments diverged from the samples in the dark treatments and the direction of the divergence depended on the browning agent with leonardite treatments associated to divergence along the first axis of the NMDS and RO treatments diverging along the second axis of the plot. Furthermore, the divergence along the leonardite-associated axis depended on the hardness of the water with soft water treatments showing no substantial divergence from the corresponding dark incubation treatments. Finally, a lesser divergence appeared for the hard water leonardite treatments of the alkalinity test, where the light exposure was shorter than in the light test (7 compared to $22 \mathrm{~d}$ ).
Biotic effects: BP and community composition

The PERMANOVA tests assessing the final bacterial community structure of both the mesocosms and the samples of the microbial test revealed substantial differences depending on the applied browning agent (Appendix 9). In addition, in the microbial test light and the interactions of light and browning agents were also significant. These results were supported by the NMDS plots of the two experiments (Fig. 3). Specifically, by the end of the mesocosms study, the primary difference between the bacterial communities depended on the addition of the leonardite product $\mathrm{HF}$, with $\mathrm{HF}$ and $\mathrm{HF}+\mathrm{RO}$ mesocosms being clearly separated from the Control and RO mesocosms along the first NMDS axis (Fig. 3b). Meanwhile, in the case of the microbial test, the interaction of light and the added browning agent was also reflected in the final bacterial community structure as visualized in the NMDS plot (Fig. 3c) and their taxonomic
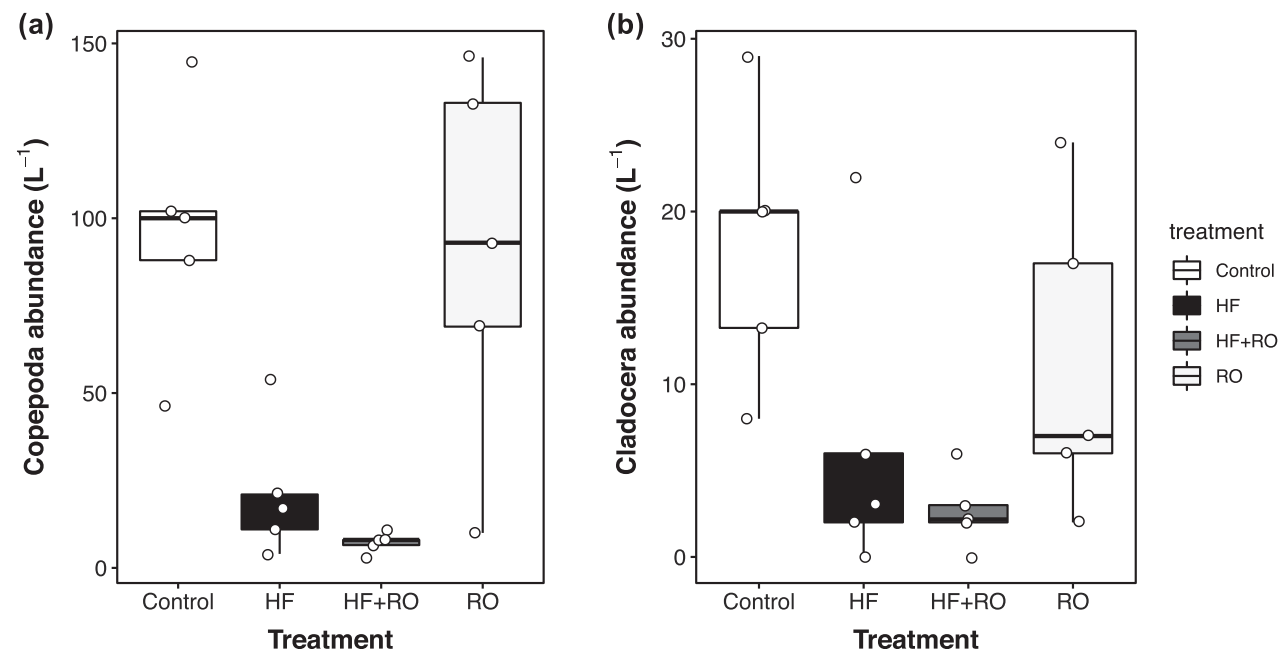

Fig 5. Mean abundance ( \pm standard error) of (a) Cladocera, and (b) Copepoda in the mesocosms with different browning agent treatments (control, $\mathrm{HF}$, $\mathrm{RO}$, and the mix of the two [HF $+\mathrm{RO}])$, approximately $16 \mathrm{~h}$ after addition of the browning agents. 
composition (Appendix 11). The communities that were incubated in dark did not differ as substantially from each other as those incubated in light. Notably, the control samples in the light treatment remained very similar to the dark incubations. In addition, RO treatments showed only some minor differences in taxonomic composition and along the second axis of the NMDS, while the leonardite amended communities (i.e., HF and $\mathrm{HF}+\mathrm{RO}$ ) in the light treatment were substantially different from the other treatments and also presented greater variation among replicates (Fig. 3c).

The heterotrophic BP measured during the light test also displayed different trends for the dark and light incubations (Fig. 4). The repeated measures ANOVA revealed significant effects of the different browning agent treatments $(\mathrm{HF}, \mathrm{RO}$, and $\mathrm{HF}+\mathrm{RO}$ ) for both, the dark and light incubations (dark: $F_{3,12}=54.21$, $p<0.001$; light: $\left.F_{3,12}=48.02, p<0.001\right)$. However, in the case of the dark incubation, there were no significant time-related differences or differences from the interaction of time and browning agent treatment (time: $F_{1,76}=0.659, p=0.419$; time $\times$ browning agent: $\left.F_{3,76}=0.397, p=0.755\right)$, while incubation in light resulted in time dependent differences (time: $F_{1,76}=16.71$, $p=0.001$; time $\times$ browning agent: $\left.F_{3,76}=2.588, p=0.059\right)$. More precisely, at the beginning of both dark and light incubations and throughout the dark treatment, the lowest BP values were measured for the HF treatments and the highest for the RO followed by the $\mathrm{HF}+\mathrm{RO}$ (Supplementary Material Appendix 12a). In the light, however, BP in the HF treatment continuously increased with time and exceeded the control values already on the fifth day $(120 \mathrm{~h})$. In addition, the $\mathrm{HF}+\mathrm{RO}$ incubations also showed different trends in light than in dark as they did not follow the declining trends of the RO incubations but instead became significantly higher by the end of the experiment (Supplementary Material Appendix 12b).

\section{Biotic effects: Zooplankton life history responses}

The abundance of zooplankton was lower in mesocosms with $\mathrm{HF}$ ( $\mathrm{HF}$ and $\mathrm{HF}+\mathrm{RO}$ ) compared to $\mathrm{RO}$ and Control (Fig. 5), with overall significant treatment effects on the abundance of Cladocera (ANOVA: $F_{3,16}=4.4043, p=0.026$ ) and Copepoda (ANOVA: $F_{3,16}=11.86, p<0.001$ ). Coefficients of linear model depicted a significant lower abundance of Cladocera, and Copepoda in HF treatments ( $\mathrm{HF}$ and HF + RO) compared to control treatment, but the zooplankton abundances in the RO treatment were not significantly different to control (Supplementary Material Appendix 13a).

In the immobilization test, we could not observe any acute immobilization of D. magna during the 48-h test period in any of the treatments. However, the different browning agents affected the reproduction of $D$. magna over the course of $21 \mathrm{~d}$. All individuals survived the experiments, but net reproductive rate, a measure that integrates fecundity, was highest in the control (64.1) and RO (57.7), and lowest in SH (52.5) and HF (45.9) treatments. The average number of offspring per clutch differed significantly between the treatments (ANOVA: $\left.F_{3,25}=8.786, p<0.001\right)$, with significantly lower numbers in all three browning agent treatments compared to the Control (Fig. 6a; Supplementary Material Appendix 13b). The number of total offspring differed significantly between the treatments (a)

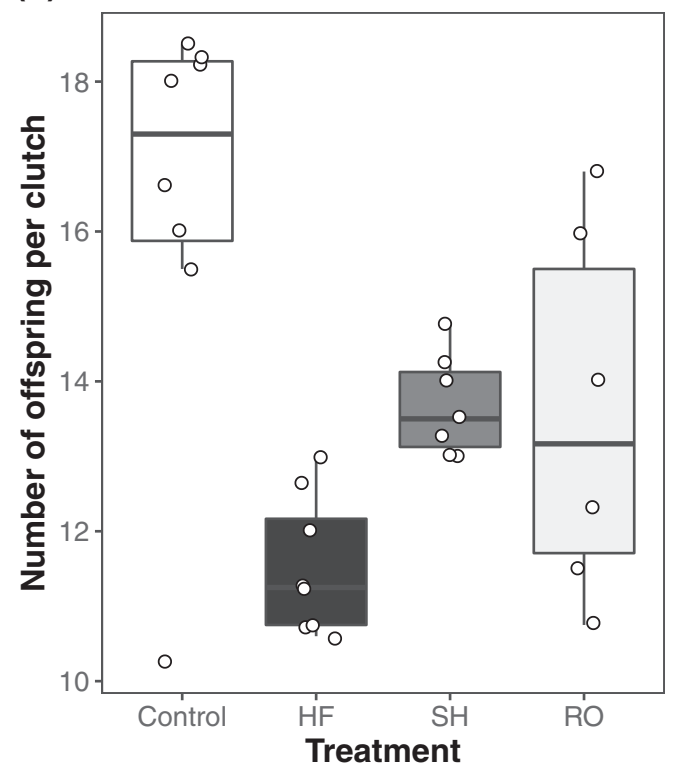

(b)

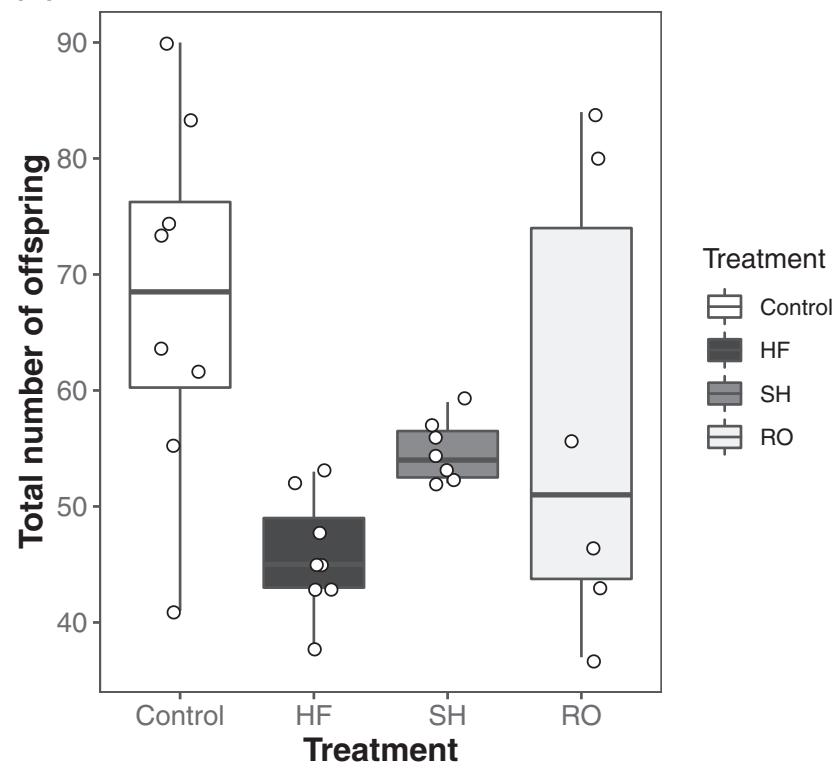

Fig 6. Fitness of $D$. magna after a 21-day reproduction test cultured under different browning agent treatments (control, leonardite containing $\mathrm{HF}$ and $\mathrm{SH}$, and RO). (a) Number of offspring per clutch and (b) total number of offspring during $21 \mathrm{~d}$. 


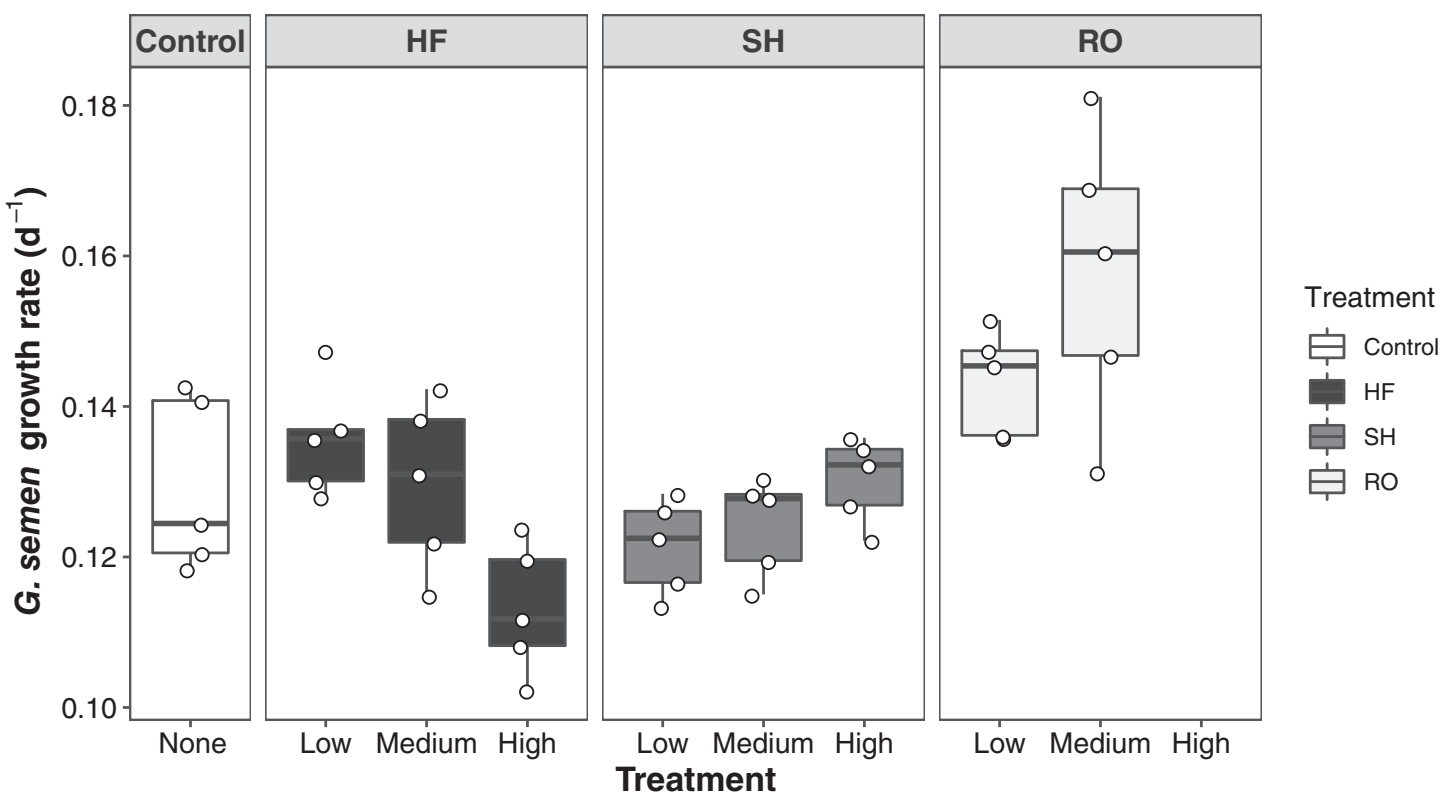

Fig 7. Growth rate of $G$. semen under different treatments of browning agents (control, leonardite containing $\mathrm{HF}$ and $\mathrm{SH}$, and RO) applied at different concentrations (low, medium, high) after $12 \mathrm{~d}$. Exclusion of high concentrations RO treatments due to flagellate contamination.

(ANOVA: $\left.F_{3,25}=4.149, p=0.002\right)$, with significantly lower number of offspring in the HF treatment compared to the Control (Fig. 6b; Supplementary Material Appendix 13c). No significant differences were found between the treatments for age at first clutch, number of clutches, or number of offspring at first clutch.

\section{Biotic effects: Growth dynamics of G. semen}

Unfortunately, replicates with high RO concentrations were contaminated by coccoid green algae likely originating from the humic stream and could not be included in the analysis. The factor browning agents had a significant effect on growth rate of $G$. semen after $12 \mathrm{~d}$ (ANOVA: $F_{8,36}: 8.085, p<0.001$; Fig. 7) and growth rate in replicates with medium concentrations of RO was significantly higher compared to the control, as indicated by the post hoc comparisons (Supplementary Material Appendix 14). Furthermore, the treatments with high concentrations of HF showed a significantly lower growth rate compared to the treatment with lower concentration. Post hoc comparisons did not show any significant effects with $\mathrm{SH}$ treatments, but a trend to a gradual increase of growth rates with increasing $\mathrm{SH}$ concentrations was visible (Fig. 7).

\section{Discussion}

In this study, we evaluated the suitability of leonardite products and a DOM concentrate obtained from a local aquatic environment in experimental studies of browning of freshwater ecosystems. We found that while leonardite products are very effective in establishing a light environment that is similar to the browning of surface waters, they have chemical characteristics that deviate from those of indigenous DOM. Consequently, we found that the leonardite product HF has biotic and abiotic effects that may bias conclusions on how browning affects ecosystems. Meanwhile, the tested DOM concentrate obtained from a local source via reverse osmosis was less efficient when it came to water color changes but had less adverse effects on water quality and biota.

\section{Chemical characteristics of browning agents}

Both $\mathrm{HF}$ and $\mathrm{SH}$ had higher concentrations of aluminum, iron, sodium, and phosphorus than RO. The multivalent cations, $\mathrm{Al}^{3+}, \mathrm{Ca}^{2+}$, and $\mathrm{Mg}^{2+}$, can stimulate particle formation and are applied as agents in drinking water purification (Matilainen et al. 2005). Although $\mathrm{HF}$ and $\mathrm{SH}$ are both leonardite products, they also had some differences with respect to the measured inorganic constituents. Browning agents had comparable calcium concentrations, but HF showed higher concentrations of all other analyzed ions. Of these, one of the most substantial differences was in aluminum, which was eight times higher in HF than in SH. Aluminum may be toxic for microbes and other organisms (Piña and Cervantes 1996), and toxicity increases with decreasing $\mathrm{pH}$. In our experiments, both lake waters had neutral to alkaline $\mathrm{pH}$, thus, toxicity of aluminum was limited. Furthermore, aluminum toxicity is connected to iron availability with low iron concentration leading to more severe toxic effects of aluminum. In HF, high aluminum was combined with high iron, and that together with high $\mathrm{pH}$ suggests low potential for toxic impacts. Finally, HF also had higher phosphorus and iron concentrations than $\mathrm{SH}$, which, if bioavailable, could also stimulate microbial and phytoplankton growth. 
The possible reasons for the variation in the composition between $\mathrm{HF}$ and $\mathrm{SH}$ could be that the leonardite used for their production comes from very different parts of the world (Germany vs. USA, respectively), and the fact that those are provided to the user in different forms. Therefore, it should be noted that especially when HF is used in manipulation studies, a range of compounds and elements are added that could provoke potential abiotic and biotic interactions. Characterization of organic constituents of browning agents by NMR and HPSEC-HRMS identified HF and SH as highly distinct from material typically observed in humic waters (e.g., SRFA from the Suwannee River), as they both lack freely dissolved carboxylic acids that are typical components of naturally occurring DOC.

\section{Abiotic effects and their consequences}

Both the mesocosm study and the microbial test demonstrated that the addition of both $\mathrm{HF}$ and RO increases water color compared to controls, with the browning effects of HF being much stronger than the effects of RO. For HF, the browning effect decreased in our mesocosms in accordance with a previous experiment, in which a weekly restocking of HF was needed in order to maintain a constant water color (UrrutiaCordero et al. 2017). We also detected a water color decrease over time in the microbial test, but in this experiment, this only happened for the samples incubated in light, suggesting that photochemical reactions caused the color loss. Notably, the effect of light was detected in borosilicate glass bottles behind conventional window glass, where light levels were moderate and light at wavelengths $<400 \mathrm{~nm}$ is very limited. Hence, most of the light that is expected to induce photochemical reactions in natural DOC was absent (Koehler et al. 2016). As typical photosynthetic primary producers were absent from the microbial communities, biological photoreactions were also unlikely.

Besides photochemical reactions, particle formation of the browning agents and subsequent export through sedimentation could also have played a role in the loss of color, as we detected an increase in particulate matter in the mesocosms and in the alkalinity test as well as POC increase in the microbial test. The increase in particulate matter and POC was detected both in dark and light and in almost all treatments including most of the controls. The alkalinity test further showed that the increase of particulate material was the highest in treatments with leonardite agents in the hard Erken water suggesting an interaction between the browning agents and the different ion concentrations (i.e., alkalinity) of the lake waters. These results are in line with the findings of Lennon et al. (2013) who estimated a loss of $5-12 \%$ of the total mass of $\mathrm{SH}$ due to particle formation. In the microbial test, the significant effect of light on POC change was caused by higher POC formation in the control and RO samples, while the extent of relative POC change was similar in light and dark for the $\mathrm{HF}$ and $\mathrm{HF}+\mathrm{RO}$ treatments. Meanwhile in the alkalinity test, the effect of light on particle formation was not significant for treatment pairs (e.g., SH in dark vs. SH in light). Overall, all these suggest that particle formation in the leonardite treatments was not affected by light making it unlikely that water color loss happened due to this process.

The microbial test provided a more likely explanation for the substantial loss in color detected for HF. The changes of TOC and DOC in the dark incubations showed that while all samples did decrease in DOC, this could be explained by flocculation only in the case of leonardite containing samples (i.e., $\mathrm{HF}$ and $\mathrm{HF}+\mathrm{RO}$ ), while the control and the RO samples did experience organic carbon loss presumably due to mineralization of organic carbon through biodegradation. The lack of significant TOC loss in the HF treatments suggests that HF was not only inert as suggested by some users (Lebret et al. 2018), but may have been inhibitory to the biological processes that could have degraded the background organic carbon in the water used for the experiment. This idea of inhibitory effects of HF was further supported by the observations on BP. BP was low in the dark treatment of the microbial experiment, as the BP values of the HF samples remained below or close to the values of the control samples. Also, the values of the $\mathrm{HF}+\mathrm{RO}$ were mostly below the samples containing RO agent only, further supporting the idea of inhibitory impact of HF to bacteria. This result also indicated that it is not possible to achieve a combined effect of the two kind of browning agents (i.e., HF: strong water color modification; RO: subsidy effect) by simply mixing them. Meanwhile, TOC loss was highest in light-exposed HF treatments (i.e., $\mathrm{HF}$ and $\mathrm{HF}+\mathrm{RO}$ ) and the HF samples had an upward trend in BP throughout the experiment with $\mathrm{BP}$ of both, $\mathrm{HF}$ and $\mathrm{HF}+\mathrm{RO}$ samples, being significantly higher at the end of the experiment compared to the other treatments. This suggests that exposure to light reduced the inhibitory effect of $\mathrm{HF}$, and made it prone to mineralization, likely via bacterial degradation and photomineralization. Although not specifically tested in this experiment, such processes could occur in treatments with other leonardite products, for example, $\mathrm{SH}$ in a similar way.

The importance of light in determining the fate of the different agents utilized in our browning experiments was corroborated by the results of both the DOM quality assessed by EEMs and the BCC. The EEM comparison of the dark and light incubations of the microbial and alkalinity tests clearly demonstrated that the major qualitative changes in DOM depended on the exposure to light, and these changes were especially related to high molecular weight substances and substances related to biological activity. Furthermore, although all browning agents were impacted by light, it affected $\mathrm{HF}$ and $\mathrm{SH}$ differently from RO. As changes in fluorescence peaks in light were the smallest for the soft water samples, a possible explanation of the impact of light could be the fact that EEM spectroscopy probes only the quality of DOC, and not POC. Hence, EEM changes may at least in part reflect the transformation of DOC to POC due to flocculation. However, one of the most substantial differences in EEM profiles between light and dark incubations were detected in the HF 
samples of the microbial test where POC formation was unaffected by light. This further supports the idea that light exposure may have initiated substantial photochemical changes in the leonardite agents other than flocculation. In support of this hypothesis, we observed significant loss in color in the HF treatments but not in the RO treatments (Fig. 1a). These results agree with Lennon et al. (2013), who proposed that the leonardite product SH may be more prone to the loss of color than DOC found in natural lakes.

\section{Biotic effects: Bacterial responses}

The light-induced change in DOM also affected the BCC. The structure of the bacterial communities that developed in the $\mathrm{HF}$ treatments (i.e., $\mathrm{HF}$ and $\mathrm{HF}+\mathrm{RO}$ treatments of the mesocosms and light test) clearly showed that this agent modified the bacterial communities more drastically when exposed to light. The lack of such drastic differences in dark incubations suggests that the exposure to light is necessary for HF to become available for utilization by bacterial communities. This idea is supported by the results of the BP measurements as well as the results of the TOC changes during the same experiment. Combined these results suggest that light exposure increased the bioavailability of HF for heterotrophic bacteria and enhanced the mineralization of this organic carbon pool. Such potential mineralization of HF upon exposure to light substantially compromises the concept of its use as an inert "sunscreen" in browning experiments.

\section{Biotic effects: Zooplankton life history responses}

In the reproduction experiment, we could not detect any stimulation of Daphnia growth by any of the tested browning agents. We therefore conclude that neither $\mathrm{HF}, \mathrm{SH}$, nor $\mathrm{RO}$ would act as a subsidy for zooplankton. On the contrary, all three browning agents had negative impacts on the zooplankton. The strongest impact was seen for HF, which in the mesocosms, reduced the abundance of Cladocera and Copepoda on average by the factor of five and nine, respectively, and had negative impacts on the reproduction of daphnids. One potential reason for the negative effects on Cladocera in the mesocosms could be the higher rates of particle formation observed in treatments with $\mathrm{HF}$, which could interfere with the filter-feeding apparatus of the Cladocera, potentially compromising their feeding and digestion. However, this would not explain the detrimental effects on Copepoda observed in the mesocosms, as these are raptorial feeders (Brandl 2005). Another potential reason for the fitness impairments of HF on zooplankton could come from stress responses. In a previous study, D. magna responded to $\mathrm{HF}$ treatments with an increase in antioxidant capacity and oxidative damage, combined with a reduced amount of energy available (Saebelfeld et al. 2017).

Despite the strong impact of HF on the zooplankton in the mesocosms, it did not have a significant impact in the acute immobilization test of cultured D. magna, although similar concentrations were used. Possibly, D. magna, as one of the biggest freshwater Cladocera species, is more tolerant against harmful substances compared to the smaller species present in a natural cladoceran community (Koivisto 1995; Saebelfeld et al. 2017). Still, all browning agents had a negative impact on the average number of offspring per clutch in the reproduction experiment. The total number of offspring was significantly lower compared to the control only in $\mathrm{HF}$, but there was a decreasing trend also for $\mathrm{SH}$ and $\mathrm{RO}$, suggesting that those may also affect Daphnia reproduction. These results are in line with a previous study that reported delayed maturity and reduced number of offspring combined with stress induction in D. magna in experiments using $\mathrm{HF}$ at a slightly higher concentration (Saebelfeld et al. 2017). This study further reported no offspring production in D. longispina at high concentrations of $\mathrm{HF}$ (30 mg DOC $\mathrm{L}^{-1}$ ). Furthermore, Bouchnak and Steinberg (2013) saw a similar trend of decreased egg production in D. magna in the presence of $\mathrm{HF}$, even at a concentration of $5 \mathrm{mg} \mathrm{C} \mathrm{L}{ }^{-1}$, but at the same time they also found that the lifespan of the Cladocera increased. Nevertheless, there are also some earlier findings that contradict the negative effects of browning agents on zooplankton observed in our experiments. In a study testing SH, Lennon et al. (2013) did not find any evidence of negative effects of $\mathrm{SH}$ on fitness of D. pulex $\times$ pulicaria clones, but in fact, reported a $10 \%$ increase in the intrinsic rate of increase in a life table experiment conducted with Daphnia. However, they note that the positive impact was marginal and that additional experiments are needed. Our combined results of the zooplankton testing suggest dramatic and negative effects of HF on the zooplankton community. This could result in strong direct and indirect effects on overall ecosystem processes with implications also for the fish and phytoplankton. Nonetheless, the underlying causes for the adverse effects of HF on zooplankton still remain elusive.

\section{Biotic effects: $G$. semen growth dynamics responses}

The effects of all three browning agents on the growth rate of $G$. semen were tested, but no negative effects could be observed, not even at high concentrations. Overall, these results indicate high tolerance of G. semen to all three substances and demonstrate a lack of toxic effects. Sassenhagen et al. (2015) showed that G. semen growth rates were only slightly reduced when light intensity was dropped from 150 to $25 \mu \mathrm{mol}$ photons $\mathrm{m}^{-2} \mathrm{~s}^{-1}$. In a mesocosm or alike, it is possible that the different browning agents could have a larger effect. Growth rates were higher in treatments with RO compared to the control. Unfortunately, the RO agents were contaminated with a green algae, demonstrating that the risk of contamination using RO can be considered high, and can be explained by its origin from an active aquatic environment. RO at intermediate concentrations furthermore showed the highest variation among replicates. Therefore, extra precautions must be taken when utilizing this agent. 


\section{Conclusion}

The purpose of this study was to evaluate the use of commercially available leonardite browning agents as an experimental analogue for indigenous DOC of terrestrial origin. Compared to RO, HF, and SH are biogeochemically highly distinct. These compounds are primarily used in experiments to mimic browning of natural waters, but our experiments with HF showed that the water color-modifying effect decreases gradually upon exposure to light. Our results suggest that besides the loss of color, light exposure also prompts other changes in DOM quality in leonardite products that lead to particulate matter formation. Furthermore, as tested for HF in light, organic carbon mineralization is enhanced, and alterations in the composition of bacterial communities are triggered. All light-induced changes substantially compromise the concept of using leonardite in browning experiments where it is expected to act as a practically inert, recalcitrant chromophore. Moreover, having chemical properties substantially different from the DOC associated with natural browning, it is also a questionable analogue of terrestrial DOC as a subsidy to aquatic ecosystems. However, as the severity of changes was related to water chemistry (e.g., alkalinity), even leonardite may be an acceptable alternative in some cases, specifically when considering the extensive work related to produce RO. For example, the extent of particle formation and the quality changes of DOM depended on the alkalinity of water with substantially fewer negative effects in soft than in hard water. Furthermore, all tested agents had negative impacts on zooplankton, with the most severe seen for HF. The impairments may be due to stress induction, but the exact mechanisms should be further investigated. Another specific problem that could arise from the use of DOM concentrates extracted from active ecosystems is the unintentional addition of local biota that as a biological contamination might bias the results of manipulation experiments, as seen from the green algae contamination in RO treatment of G. semen cultures.

In conclusion, our extensive tests of leonardite products raise multiple concerns especially on the suitability of HF as proxies for natural browning of freshwater ecosystems. Our experiments (this study, Attermeyer et al. 2019; Nydahl et al. 2019, Chaguaceda et al. unpubl.) show that it is feasible to prepare reverse osmosis concentrates for browning of several thousand liters. Hence, we recommend, (1) that browning agents derived from humic aquatic environments or soils, such as RO concentrates, should be prioritized at the laboratory scale and for mesocosms with careful consideration of potential biotic contaminations, and (2) where leonardite extracts are used, great attention should be paid to effects that may be atypical for indigenous browning agents.

\section{References}

Abate, G., and J. C. Masini. 2003. Influence of pH and ionic strength on removal processes of a sedimentary humic acid in a suspension of vermiculite. Colloid Surf. A Physicochem. Eng. Asp. 226: 25-34. doi:10.1016/S0927-7757(03)00418-7

Anderson, M. J., and D. C. I. Walsh. 2013. PERMANOVA, ANOSIM, and the mantel test in the face of heterogeneous dispersions: What null hypothesis are you testing? Ecol. Monogr. 83: 557-574. doi:10.1890/12-2010.1

Attermeyer, K., and others. 2019. Potential terrestrial influence on transparent exopolymer particle concentrations in boreal freshwaters. Limnol. Oceanogr. 64: 24552466. doi:10.1002/lno.11197

Bergström, A. K., and J. Karlsson. 2019. Light and nutrient control phytoplankton biomass responses to global change in northern lakes. Glob. Chang. Biol. 25: 2021-2029. doi: 10.1111/gcb.14623

Bouchnak, R., and C. E. W. Steinberg. 2013. Algal diets and natural xenobiotics impact energy allocation in cladocerans. I. Daphnia magna. Limnologica 43: 434-440. doi:10. 1016/j.limno.2013.01.007

Brandl, Z. 2005. Freshwater copepods and rotifers: Predators and their prey. Hydrobiologia 546: 475-489. doi:10.1007/ 1-4020-4408-9_49

Cole, J. J., and others. 2007. Plumbing the global carbon cycle: Integrating inland waters into the terrestrial carbon budget. Ecosystems 10: 171-184. doi:10.1007/s10021-006-9013-8

Cronberg, G., G. Lindmark, and S. Björk. 1988. Mass development of the flagellate Gonyostomum semen (Raphidophyta) in Swedish forest lakes - an effect of acidification? Hydrobiologia 161: 217-236. doi:10.1007/BF00044113

Drake, T. W., P. A. Raymond, and R. G. M. Spencer. 2018. Terrestrial carbon inputs to inland waters: A current synthesis of estimates and uncertainty. Limnol. Oceanogr. Lett. 3: 132-142. doi:10.1002/lol2.10055

Edgar, R. 2016. UNOISE2: Improved error-correction for Illumina $16 \mathrm{~S}$ and ITS amplicon sequencing. BioXRiv. doi: 10.1101/081257

Fee, E. J., R. E. Hecky, S. E. M. Kasian, and D. R. Cruikshank. 1996. Effects of lake size, water clarity, and climatic variability on mixing depths in Canadian Shield lakes. Limnol. Oceanogr. 41: 912-920. doi:10.4319/1o.1996.41.5.0912

Fellman, J. B., E. Hood, and R. G. M. Spencer. 2010. Fluorescence spectroscopy opens new windows into dissolved organic matter dynamics in freshwater ecosystems: A review. Limnol. Oceanogr. 55: 2452-2462. doi:10.4319/ lo.2010.55.6.2452

Geddes, P. 2009. Decoupling carbon effects and UV protection from terrestrial subsidies on pond zooplankton. Hydrobiologia 628: 47-66. doi:10.1007/s10750-009-9745-5

Guillard, R. R. L., and C. J. Lorenzen. 1972. Yellow-green algae with chlorophyllide c. J. Phycol. 8: 10-14. doi:10.1111/j. 1529-8817.1972.tb03995.x

Guillemette, F., S. L. McCallister, and P. A. del Giorgio. 2016. Selective consumption and metabolic allocation of terrestrial and algal carbon determine allochthony in lake bacteria. ISME J. 10: 1373-1382. doi:10.1038/ismej.2015.215 
Hawkes, J. A., P. J. R. Sjöberg, J. Bergquist, and L. J. Tranvik. 2019. Complexity of dissolved organic matter in the molecular size dimension: insights from coupled size exclusion chromatography electrospray ionisation mass spectrometry. Faraday Discussion. doi:10.1039/C8FD00222C

Hertkorn, N., R. Benner, M. Frommberger, P. SchmittKoppline, M. Witt, K. Kaiser, A. Kettrup, J. Hedges, and H. Harvey. 2006. Characterization of a major refractory component of marine dissolved organic matter. Geochimica et Cosmochimica Acta. 70(12):2990-3010. doi: 10.1016/j.gca.2006.03.021

Karosienè, J., J. Kasperovičienè, J. Koreivienè, K. Savadova, and I. Vitonyte. 2016. Factors promoting persistence of the bloom-forming Gonyostomum semen in temperate lakes. Limnologica 60: 51-58. doi:10.1016/j.limno.2016.05.009

Kellerman, A. M., T. Dittmar, D. N. Kothawala, and L. J. Tranvik. 2014. Chemodiversity of dissolved organic matter in lakes driven by climate and hydrology. Nat. Commun. 5: 8. doi:10. 1038/ncomms4804

Kelly, P. T., C. Solomon, B. Weidel, and S. E. Jones. 2014. Terrestrial carbon is a resource, but not a subsidy, for lake zooplankton. Ecology. 95: 1236-1242. doi:10.1890/13-1586.1

Kirk, J. T. O. 2011. Light and photosynthesis in aquatic ecosystems. Cambridge Univ. Press.

Koehler, B., E. Broman, and L. J. Tranvik. 2016. Apparent quantum yield of photochemical dissolved organic carbon mineralization in lakes. Limnol. Oceanogr. 61: 2207-2221. doi:10.1002/lno.10366

Koivisto, S. 1995. Is Daphnia magna an ecologically representatative zooplankton species in toxicity tests? Environ. Pollut. 90: 263-267. doi:10.1016/0269-7491(95) 00029-q

Kothawala, D. N., C. A. Stedmon, R. A. Müller, G. A. Weyhenmeyer, S. J. Köhler, and L. J. Tranvik. 2014. Controls of dissolved organic matter quality: Evidence from a largescale boreal lake survey. Glob. Chang. Biol. 20: 1101-1114. doi:10.1111/gcb.12488

Kritzberg, E. S., and others. 2014. Warming and browning of lakes: Consequences for pelagic carbon metabolism and sediment delivery. Freshw. Biol. 59: 325-336. doi:10.1111/ fwb. 12267

Lebret, K., S. Langenheder, N. Colinas, Ö. Östman, and E. S. Lindström. 2018. Increased water colour affects freshwater plankton communities in a mesocosm study. Aquat. Microb. Ecol. 81: 1-17. doi:10.3354/ame01858

Lennon, J. T., and K. L. Cottingham. 2008. Microbial productivity in variable resource environments. Ecology 89: 1001-1014. doi:10.1890/07-1380.1

Lennon, J. T., S. K. Hamilton, M. E. Muscarella, A. S. Grandy, K. Wickings, and S. E. Jones. 2013. A source of terrestrial organic carbon to investigate the browning of aquatic ecosystems. PLoS One 8: e75771. doi:10.1371/journal.pone. 0075771
Matilainen, A., N. Lindqvist, and T. Tuhkanen. 2005. Comparison of the efficiency of aluminium and ferric sulphate in the removal of natural organic matter during drinking water treatment process. Environ. Technol. 26: 867-875. doi:10.1080/09593332608618502

Meinelt, T., and others. 2007. Reduction in vegetative growth of the water mold Saprolegnia parasitica (Coker) by humic substance of different qualities. Aquat. Toxicol. 83: 93-103. doi:10.1016/j.aquatox.2007.03.013

Monteith, D. T., and others. 2007. Dissolved organic carbon trends resulting from changes in atmospheric deposition chemistry. Nature 450: 537-U539. doi:10.1038/ nature06316

Moran, M. A., and R. G. Zepp. 1997. Role of photoreactions in the formation of biologically labile compounds from dissolved organic matter. Limnol. Oceanogr. 42: 1307-1316. doi:10.4319/1o.1997.42.6.1307

Mostovaya, A., J. A. Hawkes, B. Köhler, T. Dittmar, and L. J. Tranvik. 2017. Emergence of the reactivity continuum of organic matter from kinetics of a multitude of individual molecular constituents. Environ. Sci. Technol. 51: 11571-11579. doi: 10.1021/acs.est.7b02876

Murphy, K. R., K. D. Butler, R. G. M. Spencer, C. A. Stedmon, J. R. Boehme, and G. R. Aiken. 2010. Measurement of dissolved organic matter fluorescence in aquatic environments: An interlaboratory comparison. Environ. Sci. Technol. 44: 9405-9412. doi:10.1021/es102362t

Muscarella, M. E., S. E. Jones, and J. T. Lennon. 2016. Species sorting along a subsidy gradient alters bacterial community stability. Ecology 97: 2034-2043. doi:10.1890/15-2026.1

Nydahl, A. C., and others. 2019. Colored organic matter increases $\mathrm{CO}_{2}$ in meso-eutrophic lake water through altered light climate and acidity. Limnol. Oceanogr. 64: 744-756. doi:10.1002/lno.11072

Oksanen, J., R. Kindt, P. Legendre, P. R. Minchin, R. B. O'Hara, G. L. Simpson, P. Solymos, M. H. H. Stevens, and H. Wagner. 2013. Vegan: Community Ecology Package. R package version 2.0-6. http:/CRAN.R-project.org/ package/vegan.

Patriarca, C., and others. 2020. Investigating the ionization of dissolved organic matter by electrospray. Anal. Chem. 92: 14210-14218. doi:10.1021/acs.analchem.0c03438

Peura, S., and others. 2014. Enhanced greenhouse gas emissions and changes in plankton communities following an experimental increase in organic carbon loading to a humic lake. Biogeochemistry 118: 177-194. doi:10.1007/s10533013-9917-2

Piña, R. G., and C. Cervantes. 1996. Microbial interactions with aluminium. Biometals 9: 311-316. doi:10.1007/BF00817932

Porcal, P., P. J. Dillon, and L. A. Molot. 2013. Photochemical production and decomposition of particulate organic carbon in a freshwater stream. Aquat. Sci. 75: 469-482. doi:10. 1007/s00027-013-0293-8 
Quilty, J. R., and S. R. Cattle. 2011. Use and understanding of organic amendments in Australian agriculture: A review. Soil Res. 49: 1-26. doi:10.1071/SR10059

R Core Team. 2018. R: A language and environment for statistical computing. R Foundation for Statistical Computing, Vienna, Austria. http://www.R-project.org/

Rengefors, K., G. A. Weyhenmeyer, and I. Bloch. 2012. Temperature as a driver for the expansion of the microalga Gonyostomum semen in Swedish lakes. Harmful Algae 18: 65-73. doi:10.1016/j. hal.2012.04.005

Saebelfeld, M., L. Minguez, J. Griebel, M. O. Gessner, and J. Wolinska. 2017. Humic dissolved organic carbon drives oxidative stress and severe fitness impairments in Daphnia. Aquat. Toxicol. 182: 31-38. doi:10.1016/j.aquatox.2016.11.006

Sassenhagen, I., S. Wilken, A. Godhe, and K. Rengefors. 2015. Phenotypic plasticity and differentiation in an invasive freshwater microalga. Harmful Algae 41: 38-45. doi:10. 1016/j.hal.2014.11.001

Serkiz, S. M., and E. M. Perdue. 1990. Isolation of dissolved organic-matter from the Suwannee river using reverse-osmosis. Water Res. 24: 911-916. doi:10.1016/0043-1354(90)90142-s

Segura, J., M. B. Nilsson, J. Schleucher, M. Haei, T. Sparrman, A. J. Szekely, S. Bertilsson, and M. G. Öquist 2019. Microbial utilization of simple carbon substrates in boreal peat soils at low temperatures. Soil Biology and Biochemistry. 135: 438448. doi:10.1016/j.soilbio.2019.06.006

Smith, C. E., and F. Azam. 1992. A simple, economical method for measuring bacterial protein synthesis rates in seawater using 3H-leucine. Mar. Microb. Food Webs 6: 107-114.

Sobek, S., G. Algesten, A. K. Bergstrom, M. Jansson, and L. J. Tranvik. 2003. The catchment and climate regulation of $\mathrm{pCO}_{2}$ in boreal lakes. Glob. Chang. Biol. 9: 630-641. doi: 10.1046/j.1365-2486.2003.00619.x

Solomon, C. T., and others. 2015. Ecosystem consequences of changing inputs of terrestrial dissolved organic matter to lakes: Current knowledge and future challenges. Ecosystems 18: 376-389. doi:10.1007/s10021-015-9848-y

Swedish National Data Service. 2020. Water chemistry data from Erken from 1989 till 2015. https://snd.gu.se/en/ catalogue/study/ecds0205\#dataset

Székely, A. J., M. Berga, and S. Langenheder. 2013. Mechanisms determining the fate of dispersed bacterial communities in new environments. ISME J. 7: 61-71. doi:10.1038/ ismej.2012.80

Tranvik, L. J., J. J. Cole, and Y. T. Prairie. 2018. The study of carbon in inland waters-from isolated ecosystems to players in the global carbon cycle. Limnol. Oceanogr. Lett. 3: 41-48. doi:10.1002/lol2.10068

Urrutia-Cordero, P., and others. 2017. Phytoplankton diversity loss along a gradient of future warming and brownification in freshwater mesocosms. Freshw. Biol. 62: 1869-1878. doi: $10.1111 /$ fwb.13027
Vasconcelos, F. R., S. Diehl, P. Rodriguez, P. Hedström, J. Karlsson, and P. Byström. 2019. Bottom-up and top-down effects of browning and warming on shallow lake food webs. Glob. Chang. Biol. 25: 504-521. doi:10.1111/gcb. 14521

von Wachenfeldt, E., D. Bastviken, and L. J. Tranvik. 2009. Microbially induced flocculation of allochthonous dissolved organic carbon in lakes. Limnol. Oceanogr. 54: 1811-1818. doi:10.4319/1o.2009.54.5.1811

von Wachenfeldt, E., S. Sobek, D. Bastviken, and L. J. Tranvik. 2008. Linking allochthonous dissolved organic matter and boreal lake sediment carbon sequestration: The role of light-mediated flocculation. Limnol. Oceanogr. 53: 24162426. doi:10.2307/40058332

Weidel, B. C., K. Baglini, S. E. Jones, P. T. Kelly, C. T. Solomon, and J. A. Zwart. 2017. Light climate and dissolved organic carbon concentration influence species-specific changes in fish zooplanktivory. Inland Waters 7: 210-217. doi:10.1080/20442041.2017.1329121

Wetzel, R. G., P. G. Hatcher, and T. S. Bianchi. 1995. Natural photolysis by ultraviolet irradiance of recalcitrant dissolved organic matter to simple substrates for rapid bacterial metabolism. Limnol. Oceanogr. 40: 1369-1380.

Weyhenmeyer, G. A., R. A. Müller, M. Norman, and L. J. Tranvik. 2016. Sensitivity of freshwaters to browning in response to future climate change. Clim. Change 134: 225-239. doi:10.1007/s10584-015-1514-Z

Williamson, C. E., and others. 2015. Ecological consequences of long-term browning in lakes. Sci. Rep. 5: 10. doi:10. 1038/srep 18666

\section{Acknowledgments}

Financial support was received from the Knut and Alice Wallenberg Foundation for funding to L.J.T. (grant KAW 2013.0091). A.J.S. was supported by grants from the Swedish Research Council Formas and a Marie Curie International Outgoing Fellowship within the $7^{\text {th }}$ European Community Framework Programme. We are extremely grateful to all those people involved in maintaining and sampling the mesocosms, especially William Colom Montero, Fernando Chaguaceda, Sara Andersson, Carolin Hiller, and Holger Villwock for all the help in the field and the laboratory. Thanks also to Don Pierson, Björn Mattson, and Christer Strandberg for technical assistance and to Jean Pettersson, Helena Enderskog, Kristiina Mustonen, and Erika Bridell for help with laboratory analyses. Mafalda Castro gave valuable insight and guidance in Daphnia culturing. Judita Koreiviene provided the $G$. semen monoculture. Open access funding enabled and organized by Projekt DEAL.
Submitted 23 February 2021 Revised 20 September 2021 Accepted 27 September 2021

Associate editor: Krista Longnecker 